\title{
Metaplastic Regulation of CA1 Schaffer Collateral Pathway Plasticity by Hebbian MGluR1a- Mediated Plasticity at Excitatory Synapses onto Somatostatin-Expressing Interneurons ${ }^{1,2,3}$
}

\author{
Cristina Vasuta, (DJulien Artinian, Isabel Laplante, Sarah Hébert-Seropian, Karim Elayoubi, and (1)Jean- \\ Claude Lacaille
}

DOI:http://dx.doi.org/10.1523/ENEURO.0051-15.2015

Groupe de Recherche sur le Système Nerveux Central and Department of Neuroscience, Faculty of Medicine, Université de Montréal, Montreal, Quebec H3T 1J4, Canada

\begin{abstract}
Cortical GABAergic interneurons represent a highly diverse neuronal type that regulates neural network activity. In particular, interneurons in the hippocampal CA1 oriens/alveus (O/A-INs) area provide feedback dendritic inhibition to local pyramidal cells and express somatostatin (SOM). Under relevant afferent stimulation patterns, they undergo long-term potentiation (LTP) of their excitatory synaptic inputs through multiple induction and expression mechanisms. However, the cell-type specificity of these different forms of LTP and their specific contribution to the dynamic regulation of the CA1 network remain unclear. Here we recorded from SOM-expressing interneurons (SOM-INs) in the O/A region from SOM-Cre-Ai3 transgenic mice in whole-cell patch-clamp. Results indicate that, like in anatomically identified O/A-INs, theta-burst stimulation (TBS) induced a Hebbian form of LTP dependent on metabotropic glutamate receptor type 1a (mGluR1a) in SOM-INs, but not in parvalbumin-expressing interneurons, another mainly nonoverlapping interneuron subtype in CA1. In addition, we demonstrated using field recordings from transgenic mice expressing archaerhodopsin 3 selectively in SOM-INs, that a prior conditioning TBS in O/A, to induce mGluR1a-dependent LTP in SOM-INs, upregulated LTP in the Schaffer collateral pathway of pyramidal cells. This effect was prevented by light-induced hyperpolarization of SOM-INs during TBS, or by application of the mGluR1a antagonist LY367385, indicating a necessity for mGluR1a and SOM-INs activation. These results uncover that SOM-INs perform an activity-dependent metaplastic control on hippocampal CA1 microcircuits in a cell-specific fashion. Our findings provide new insights on the contribution of interneuron synaptic plasticity in the regulation of the hippocampal network activity and mnemonic processes.
\end{abstract}

Key words: hippocampus; LTP; metaplasticity; mGluR1a; somatostatin-interneuron

\section{Significance Statement}

Long-term potentiation (LTP) is an important cellular mechanism of learning and memory. Although it has been extensively characterized in principal cells of the hippocampus, it also occurs in inhibitory GABAergic interneurons, known to orchestrate hippocampal network activity. Interneurons are highly diverse and many subtypes are distinguished, endowed with distinct functions. However, their cell-type-specific contribution and how LTP in these interneurons regulate hippocampal CA1 microcircuits remain open questions. Here, we found that LTP occurring in the Schaffer collateral pathway of CA1 pyramidal cells was upregulated by prior induction of mGluR1a-dependent LTP in somatostatin-expressing interneurons. These results reveal a metaplastic control of the hippocampal CA1 network which can help to understand interneuron subtypespecific contribution in hippocampus-dependent learning and memory. 


\section{Introduction}

Information processing within the cerebral cortex relies on complex microcircuits of interconnected excitatory glutamatergic principal cells and inhibitory GABAergic interneurons. Comprising $10-20 \%$ of the total cortical neuronal population, GABAergic interneurons dynamically regulate neural networks by controlling the amount of excitation that neurons receive, by synchronizing their outputs and supporting brain oscillations (for review, see Mann and Paulsen, 2007; Klausberger and Somogyi, 2008). GABAergic interneurons are highly heterogeneous and multiple subtypes can be distinguished on the basis of their morphological, neurochemical, physiological, and developmental properties, which is particularly well documented in the hippocampus (Tricoire et al., 2011; Hosp et al., 2014; for review, see Freund and Buzsáki, 1996; Klausberger and Somogyi, 2008; Kepecs and Fishell, 2014).

Long-term potentiation (LTP) is an activity-dependent long-lasting change of the synaptic strength and is thought to be a key element in the cellular processes of learning and memory (for review, see Kandel et al., 2014; Lynch et al., 2014). Although LTP presents relatively stereotyped mechanisms in excitatory principal neurons, several different forms of LTP have been described at excitatory synapses onto hippocampal GABAergic interneurons (Ouardouz and Lacaille, 1995; Hainmuller et al., 2014; for review, see Pelletier and Lacaille, 2008; Kullmann et al., 2012; Topolnik, 2012). Particularly interesting are interneurons from the CA1 region, which have their cell body located in the stratum oriens, provide a dendritic inhibition to their pyramidal and interneuron targets and express somatostatin (SOM; also called SST; Tricoire et al., 2011; for review, see Freund and Buzsáki, 1996; Klausberger and Somogyi, 2008; Müller and Remy, 2014). Notably, NMDA receptor (NMDAR)-independent LTP, which depends on the type 1a metabotropic glutamate receptor (mGluR1a; Perez et al., 2001; Lapointe et al., 2004; Le Duigou and Kullmann, 2011) and on a postsynaptic $\mathrm{Ca}^{2+}$ rise from multiple sources (Topolnik et al., 2006; Lamsa et al., 2007; Oren et al., 2009; Croce

Received May 11, 2015; accepted August 6, 2015; First published August 12, 2015.

${ }^{1}$ The authors declare no competing financial interests.

${ }^{2}$ Author contributions: C.V., J.A., and J.-C.L. designed research; C.V., J.A., I.L., S.H.-S., and K.E. performed research and analyzed data; C.V., J.A., I.L., and J.-C.L. wrote the paper.

${ }^{3}$ This work was supported by the Canadian Institutes of Health Research (operating grant to J.-C.L.; MOP-10848), the Fonds de la Recherche du Québec en Santé [FRQS Group grant to J.-C.L.; Groupe de Recherche sur le Système Nerveux Central (GRSNC)]. J.-C.L. is the recipient of the Canada Research Chair in Cellular and Molecular Neurophysiology. C.V. and J.A. were supported by a GRSNC Fellowship, and S.H.-S. by a Studentship from CIHR.

Correspondence should be addressed to Dr Jean-Claude Lacaille, Département de Neurosciences, Faculté de Médecine, Université de Montréal, Case Postale 6128, Succursale Centre-Ville, Montréal, QC H3C 3J7, Canada. Email: jean-claude.lacaille@umontreal.ca.

DOI:http://dx.doi.org/10.1523/ENEURO.0051-15.2015

Copyright (C) 2015 Vasuta et al.

This is an open-access article distributed under the terms of the Creative Commons Attribution 4.0 International, which permits unrestricted use, distribution and reproduction in any medium provided that the original work is properly attributed. et al., 2010), has been described in interneurons from the $\mathrm{CA} 1$ oriens/alveus region (O/A-IN) and in SOM-expressing interneurons (SOM-INs) from the O/A region (Szabo et al., 2012). Furthermore, LTP occurrence and rules appear to be highly cell-type-specific (Perez et al., 2001; Lamsa et al., 2007; Nissen et al., 2010; Szabo et al., 2012), adding an important level of complexity in our understanding of interneuron diversity.

At the network level, hippocampal CA1 O/A-INs are mainly activated by recurrent excitation from local pyramidal cells and act in an integrator mode as they inhibit distal dendrites in proportion to the rate of the synaptic inputs (Pouille and Scanziani, 2004). Furthermore, SOMINs have been shown to specifically and dynamically regulate input-output transformations and to gate burst firing in pyramidal cells (Lovett-Barron et al., 2012). However, although oriens-lacunosum/moleculare (OLM) cells, a subset of SOM-INs in the O/A region, inhibit the pyramidal distal dendritic tuft, they also inhibit Schaffer collateral-associated GABAergic interneurons (Leão et al., 2012). Indeed, specific activation of OLM cells promotes a disinhibition of pyramidal neurons, increasing their responsiveness to Schaffer collateral inputs, and facilitates LTP at these synapses. In addition, these cells prevent LTP in the temporo-ammonic pathway, conferring them the ability to bidirectionally modulate CA1 plasticity (Leão et al., 2012). But how long-term plasticity occurring at excitatory synapses onto SOM-INs modulates network activity of pyramidal cells remains largely unknown. mGluR1a-dependent LTP occurring at excitatory inputs onto O/A-INs increases GABAergic inhibition of principal neurons (Lapointe et al., 2004) and NMDAR-dependent LTP induced in CA1 stratum radiatum interneurons maintains the temporal fidelity of input and output signals of pyramidal cells (Lamsa et al., 2005). Beyond the proper characterization of the different forms of LTP occurring in multiple interneuron subtypes, their specific contribution to the CA1 network regulation, especially in gating of LTP at Schaffer collateral-pyramidal cell synapses, remains an open question.

In this study, we address this question, first by assessing the cell-specificity of Hebbian mGluR1a-dependent LTP in two populations of interneurons within the hippocampal CA1 area: the SOM-INs and the parvalbuminexpressing interneurons (PV-INs), using mice lines expressing Cre recombinase under the control of either the SOM or the PV promoter. We found that theta-burst stimulation (TBS) induced Hebbian mGluR1a-dependent LTP in SOM-INs in a cell-specific fashion. Next, we establish the functional significance of the SOM-IN synaptic plasticity for network activity. We uncovered that prior induction of this form of LTP at excitatory synapses onto SOM-INs upregulated LTP in the Schaffer collateral pathway of CA1 pyramidal cells, establishing a cell-specific metaplastic control of the CA1 microcircuit by SOM-INs.

\section{Materials and Methods}

All animal procedures and experiments were performed in accordance with the Université de Montréal animal care committee's regulations. 


\section{Transgenic mice lines}

SOM-IRES-Cre mice were kindly provided by Z. J. Huang (Cold Spring Harbor Laboratory, Cold Spring Harbor, NY; JAX no. 013044; Taniguchi et al., 2011). PV-Cre mice (JAX no. 008069), the Cre-reporter expressing the enhanced yellow fluorescent protein (EYFP) Ai3 mice (JAX no. 007903) and the ArChR3/GFP Ai35 mice (JAX \#012735) were purchased from Jackson Laboratories. Experiments were performed in mice of either sex.

\section{Interneuron distribution and immunofluorescence}

To fluorescently label SOM-INs, heterozygous SOMIRES-Cre;Ai3-EYFP mice were obtained by crossing SOM-IRES-Cre and Ai3-EYFP mice. To label PV-INs, heterozygous PV-Cre;Ai3-EYFP mice were generated by crossing PV-Cre and Ai3-EYFP mice. Distribution of EYFP-labeled interneurons and colocalization with somatostatin or parvalbumin were determined by combination of fluorescence microscopy and immunohistochemistry. SOM-IRES-Cre;Ai3-EYFP mice (3- to 5-weeks-old) and PV-Cre;Ai3-EYFP mice (6- to 8-weeks-old) were deeply anesthetized intraperitoneally with sodium pentobarbital (MTC Pharmaceuticals), perfused transcardially with icecold $0.1 \mathrm{M}$ phosphate buffer $(\mathrm{PB})$ and $4 \%$ paraformaldehyde in $0.1 \mathrm{M}$ PB (PFA) and the brain isolated. Postfixed brains were cryoprotected in $30 \%$ sucrose and coronal brain sections (50 $\mu \mathrm{m}$ thick) were obtained using a freezing microtome (Leica SM200R). Sections were permeabilized with $0.2-0.5 \%$ Triton $X-100$ in PBS (15 min) and unspecific binding was blocked with $10 \%$ normal goat serum in $0.1-0.3 \%$ Triton X-100/PBS (1 h). Rabbit polyclonal somatostatin 28 (1/2000; Abcam) or mouse monoclonal parvalbumin (1/5000; Millipore) antibodies were incubated overnight at $4^{\circ} \mathrm{C}$. Sections were subsequently incubated at room temperature with AlexaFluor 594conjugated goat anti-rabbit lgGs (1/500; 90 min; Jackson ImmunoResearch Laboratories) or rhodamine-conjugated goat anti-mouse IgG1 (1/200; 90 min; Jackson ImmunoResearch Laboratories). Hippocampal sections were examined using a Nikon microscope (Nikon Eclipse E600) equipped with epifluorescence and images were acquired with the Simple PCl software (Clmaging Systems).

\section{Slices and whole-cell recordings}

Hippocampal slices were prepared from 4- to 8-weekold SOM-IRES-Cre;Ai3-EYFP mice and 6- to 8-week-old PV-Cre;Ai3-EYFP mice. Animals were anesthetized with isoflurane and the brain was rapidly excised and placed in ice-cold sucrose-based cutting solution saturated with $95 \% \mathrm{O}_{2}$ and $5 \% \mathrm{CO}_{2}$ containing the following (in $\mathrm{mm}$ ): 87 $\mathrm{NaCl}, 2.5 \mathrm{KCl}, 1.25 \mathrm{NaH}_{2} \mathrm{PO}_{4}, 7 \mathrm{MgSO}_{4}, 0.5 \mathrm{CaCl}_{2}, 25$ $\mathrm{NaHCO}_{3}, 25$ glucose, 11.6 ascorbic acid, 3.1 pyruvic acid,

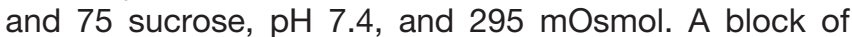
tissue containing the hippocampus was prepared and transverse hippocampal slices (300 $\mu \mathrm{m}$ thick) were cut on a vibratome (Leica VT1000S). Slices were transferred to oxygenated artificial CSF (ACSF) at room temperature containing the following (in $\mathrm{mm}$ ): $124 \mathrm{NaCl}, 2.5 \mathrm{KCl}, 1.25$ $\mathrm{NaH}_{2} \mathrm{PO}_{4}, 4 \mathrm{MgSO}_{4}, 4 \mathrm{CaCl}_{2}, 26 \mathrm{NaHCO}_{3}$, and 10 glucose, $\mathrm{pH}$ 7.3-7.4, and 295-305 mOsmol, allowed to recover for at least $1 \mathrm{~h}$, and transferred for experiments to a submersion chamber perfused $(2 \mathrm{ml} / \mathrm{min}$ ) with ACSF at 31 $\pm 0.5^{\circ} \mathrm{C}$. Prior to recordings, $\mathrm{CA} 1$ and $\mathrm{CA} 3$ regions were isolated by a surgical cut. EYFP-expressing CA1 interneurons were identified using an upright microscope (Nikon Eclipse, E600FN), equipped with a water-immersion longworking distance objective (40×, Nomarski Optics), epifluorescence and an infrared video camera. Whole-cell voltage-clamp recordings were obtained using borosilicate glass pipettes (3-6 M $\Omega$ ) filled with intracellular solution containing the following (in mM): $130 \mathrm{CsMeSO}_{3}, 5$ $\mathrm{NaCl}, 1 \mathrm{MgCl}_{2}, 10$ phosphocreatine, 10 HEPES, 2 ATPTris, 0.4 GTP-Tris, 0.1 spermine, 2 QX314, and $0.1 \%$ biocytin, pH 7.2-7.3, and 275-285 mOsmol. For wholecell current-clamp recordings of intrinsic properties, the intracellular solution contained the following (in $\mathrm{mM}$ ): 150 K-gluconate, $3 \mathrm{MgCl}_{2}$, 0.5 EGTA, 10 HEPES, 2 MgATP, $0.3 \mathrm{NaGTP}$, and $0.1 \%$ biocytin, $\mathrm{pH} 7.4$, and 300 mOsmol (Fig. 2). For recordings of synaptic potentials, the intracellular solution contained the following (in $\mathrm{mm}$ ): 120 $\mathrm{KMeSO}_{4}, 10 \mathrm{KCl}, 0.5$ EGTA, 10 HEPES, $2.5 \mathrm{MgATP}, 0.3$ NaGTP, 10 Na2-phosphocreatine, 0.1 spermine, and $0.1 \%$ biocytin, $\mathrm{pH}$ 7.3-7.4, and $280 \pm 5$ mOsmol (Fig. 5). Data was acquired using a Multiclamp 700B amplifier (Molecular Devices) and digitized using Digidata 1440A and pClamp 10 (Molecular Devices). Recordings were low-pass filtered at $2 \mathrm{kHz}$ and digitized at $20 \mathrm{kHz}$. Series resistance was regularly monitored during experiments and data were included only if the holding current and series resistance were stable.

Membrane properties of EYFP-labeled SOM-INs were measured in current-clamp recordings (Tricoire et al., 2011). Resting membrane potential was measured with the holding current $I=0 \mathrm{pA}$ immediately after break-in in whole-cell configuration. Input resistance $(R \mathrm{~m})$ was measured using a linear regression of voltage deflections $( \pm 15$ $\mathrm{mV}$ ) in response to current steps of $5 \mathrm{pA}$ increment (holding membrane potential $-60 \mathrm{mV}$ ). Membrane time constant was calculated from the mean responses to 20 successive hyperpolarizing current pulses (20 pA; $400 \mathrm{~ms}$ ) and was determined by fitting voltage responses with a single exponential function. Action potential (AP) threshold was taken as the voltage at which the slope trajectory reached $10 \mathrm{mV} / \mathrm{ms}$, whereas AP amplitude was the difference in membrane potential between threshold and peak; these properties were measured for the first AP elicited by a depolarizing 800-ms-long current pulse just sufficient to bring the cell to threshold for AP generation. Firing frequency was calculated from the AP number during an AP train elicited by an 800-ms-long current injection at twice threshold. The sag index was determined from a series of negative current steps (800 ms duration). From the $V-I$ plots, the peak negative voltage deflection (Vhyp) and the steady-state voltage deflection (Vsag, calculated for the last $200 \mathrm{~ms}$ of the current step) were used to calculate the index as the ratio Vrest - Vsag/Vrest Vhyp, for current injections corresponding to $V$ sag $=-80$ $\mathrm{mV}$.

EPSCs were evoked in interneurons using constant current pulses (50 $\mu$ s duration) via an ACSF-filled bipolar theta-glass electrode positioned approximately $100 \mu \mathrm{m}$ 
lateral to the recorded cell soma. EPSCs were recorded in the presence of (2R)-amino-5-phosphonovaleric acid (AP5; $50 \mu \mathrm{M})$ and gabazine $(5 \mu \mathrm{M})$ to block NMDA and $\mathrm{GABA}_{\mathrm{A}}$ receptors, respectively. Putative single-fiber EPSCs were evoked at $0.5 \mathrm{~Hz}$ using minimal stimulation (failure rate $>50 \%$ ). LTP was induced by three episodes (given at $30 \mathrm{~s}$ intervals) of TBS of afferent fibers (5 bursts each consisting of 4 pulses at $100 \mathrm{~Hz}$ with 250 ms interburst interval) paired with postsynaptic depolarization (5 depolarizing steps to $-20 \mathrm{mV}, 60 \mathrm{~ms}$ long). EPSPs were evoked at $0.1 \mathrm{~Hz}$ using constant current pulses (50 $\mu \mathrm{s}$ duration) through a concentric bipolar $\mathrm{Pt} / \mathrm{Ir}$ electrode (FHC) positioned in the stratum oriens close to the alveus, approximately $100 \mu \mathrm{m}$ lateral to the recorded cell soma. Membrane potential was held at $-60 \mathrm{mV}$ by constant current injection. EPSPs were evoked during a hyperpolarizing current step (5-10 mV, 0.5-1 s duration) to avoid action potential generation. LTP was induced by the same TBS protocol described above for voltage-clamp experiments, except that it was not paired with any postsynaptic depolarization or hyperpolarization. EPSPs were recorded in ACSF in the absence of the antagonists AP5 and gabazine. In some experiments, LY367385 (40 $\mu \mathrm{M}$; Tocris Bioscience) was added to the extracellular solution. EPSCs and EPSPs were usually characterized in one cell per slice, and the different experimental conditions were interleaved. Responses were analyzed off-line using Clampfit (pClamp 10; Molecular Devices), GraphPad, and OriginPro 8. Amplitude of EPSC and EPSP (average response including failures), failure rate (failures/total stimulations), and potency (amplitude excluding failures) of EPSCs, were averaged in 5 min bins over the total $35 \mathrm{~min}$ period of recordings.

\section{Field potential recordings and optogenetics}

To express archaerhodopsin-3/GFP (ArChR3/GFP) in somatostatin interneurons, heterozygous SOM-IRES-Cre; ArChR3/GFP mice were obtained by crossing SOM-IRESCre and ArChR3/GFP Ai35 mice. For experiments with field potential recordings, transverse hippocampal slices (400 $\mu \mathrm{m}$ thickness) were prepared from SOM-IRES-Cre; ArChR3/GFP mice as described above, except ice-cold oxygenated ACSF containing $1.3 \mathrm{mM} \mathrm{MgSO}_{4}$ and $2.5 \mathrm{mM}$ $\mathrm{CaCl}_{2}$. The slices were allowed to recover for at least $2 \mathrm{~h}$ at $32^{\circ} \mathrm{C}$ in ACSF, and for an additional 30 minutes at $27^{\circ}-28^{\circ} \mathrm{C}$ while submerged in a recording chamber continuously perfused (2-2.5 $\mathrm{ml} / \mathrm{min}$ ) with ACSF. Field EPSPs (fEPSPS) were recorded in CA1 stratum radiatum with glass electrodes (1-2.5 M 2 ) filled with ASCF. Schaffer collaterals were stimulated ( $0.1 \mathrm{~ms}$ duration; $\left.30 \mathrm{sec}^{-1}\right)$ using a concentric bipolar tungsten stimulating electrode (FHC) placed in stratum radiatum proximal to the CA3 region. A second concentric bipolar tungsten stimulating electrode was positioned in the oriens-alveus junction proximal to the subiculum for theta-burst conditioning trains (as described above). Field potentials were recorded with a differential extracellular amplifier (Microelectrode AC Amplifier Model 1800, A-M Systems), filtered at $2 \mathrm{kHz}$, digitized at $10 \mathrm{kHz}$ (Digidata 1440A), and analyzed with pClamp10 (Molecular Devices). Stimulus intensity was adjusted to elicit $50 \%$ of maximal fEPSP. fEPSP slope was measured at $10-90 \%$ of fEPSP amplitude.

LTP was induced at CA1 Schaffer collateral synapses by high-frequency stimulation (HFS) using a train (1s duration) of $100 \mathrm{~Hz}$ pulses. A conditioning TBS consisting of three episodes (given at $30 \mathrm{~s}$ intervals) of five bursts (each consisting of four pulses at $100 \mathrm{~Hz}$ with $250 \mathrm{~ms}$ interburst interval) was applied at the oriens/alveus border to induce plasticity in SOM-INs in stratum oriens. ArChR3 was activated by illumination using a light guide positioned above the slice (590 nm yellow light, custom-made LED system). The measured LED power was $26 \mathrm{~mW}$ at the end of a $1 \mathrm{~mm}$ light guide. Data are expressed as mean \pm SEM.

\section{Results}

\section{Distribution of YFP-labeled interneurons and specific colocalization with SOM and PV}

SOM-INs or PV-INs were specifically labeled by breeding Ai3-EYFP reporter mice with SOM-IRES-Cre or PVCre mice, respectively. The distribution of EYFP-labelled SOM-INs and PV-INs interneurons was examined by fluorescence microscopy and their colocalization with somatostatin or parvalbumin was determined by immunofluorescence. Consistent with previous work (for review, see Freund and Buzsáki, 1996), the distribution of SOM-INs and PV-INs in the CA1 hippocampus was mostly nonoverlapping. EYFP-labeled SOM-IN somas were located mostly in stratum oriens and alveus of the CA1 and CA3 regions, as well as in the hilus of the dentate gyrus (Fig. 1A). EYFP-labeled PV-IN somas were mainly found in and around the pyramidal cell layer of CA1 and CA3 regions, and the granule cell layer of the dentate gyrus (Fig. 1B). We next verified the cell-specificity of the EYFP-labeling of CA1 interneurons by immunofluorescence. In SOM-IRES-Cre;Ai3-EYFP mice (Fig. 1C), 98.5\% of EYFP-labeled interneurons in the CA1 region were immunopositive for somatostatin ( $n=323$ cells, 3 animals from 2 different litters), whereas only $6.9 \%$ of them were positive for parvalbumin $(n=354)$. In contrast in PV-Cre; Ai3-EYFP mice (Fig. 1D), 97.8\% of EYFP-labeled CA1 interneurons were immunopositive for parvalbumin $(n=$ 267 cells, 3 animals from 2 different litters), and only $10.7 \%$ were positive for somatostatin ( $n=193$ cells), thus confirming the specific labeling of mostly nonoverlapping CA1 populations of dendrite-projecting SOM-INs and perisomatic projecting PV-INs (Freund and Buzsáki, 1996; Tricoire et al., 2011) in the mice lines.

\section{LTP at the excitatory synapses onto SOM-INs}

Next we made use of SOM-IRES-Cre;Ai3-EYFP mice to determine whether the Hebbian LTP described at synapses onto CA1 oriens-alveus interneurons (Perez et al., 2001) occurs at excitatory synapses onto SOM-INs. First we characterized with whole-cell current-clamp recordings the membrane properties of CA1 EYFP-labeled SOM-INs (Fig. 2). The resting membrane potential was $-58.3 \pm 1.9 \mathrm{mV}(n=8)$, the membrane resistance was $194.8 \pm 20.6 \mathrm{M} \Omega(n=9)$, the membrane time constant 
A

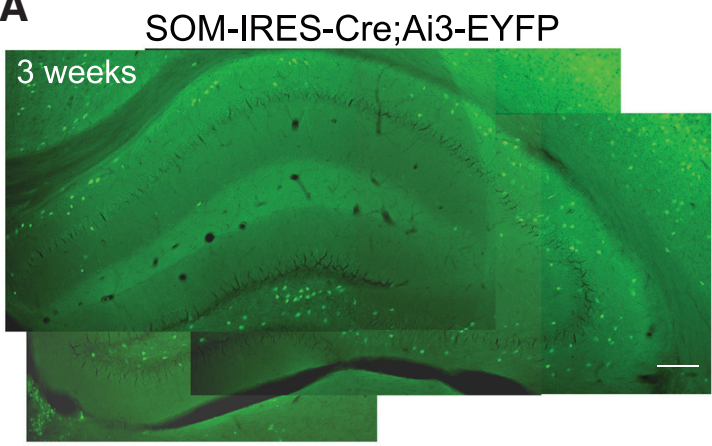

C
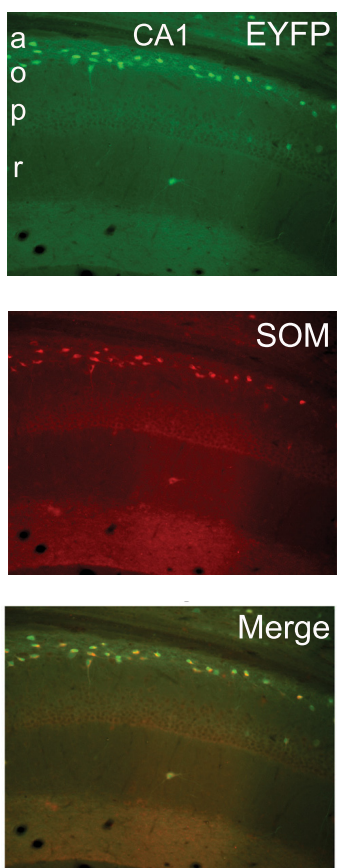
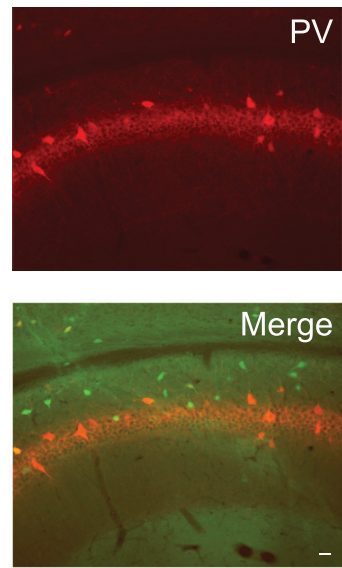

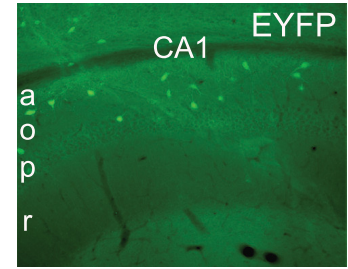

B

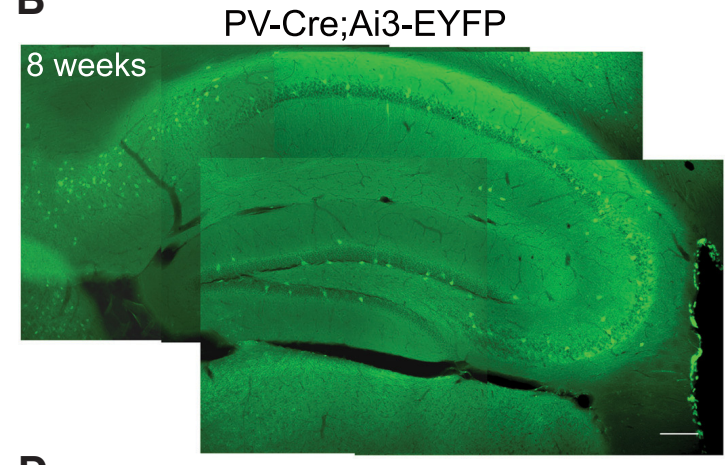

D
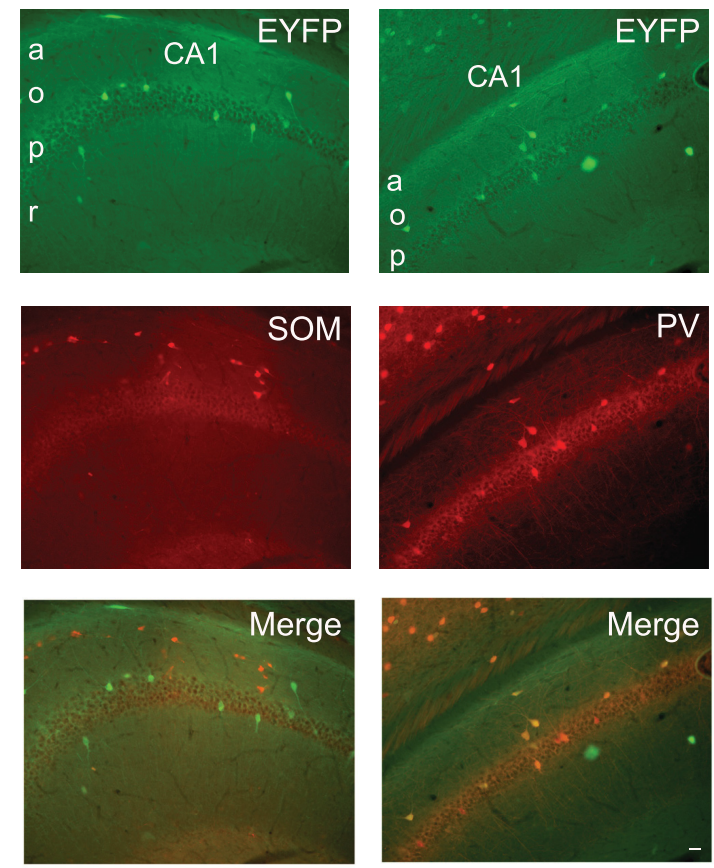

Figure 1. Distribution of EYFP-labeled CA1 interneurons and specific colocalization with SOM and PV. A, B, Montage of fluorescence images showing the mostly nonoverlapping distribution of EYFP-labeled INs in the hippocampus from SOM-IRES-Cre; Ai3-EYFP $(\boldsymbol{A})$ and PV-Cre;Ai3-EYFP $(\boldsymbol{B})$ mice. Scale bars, $100 \mu \mathrm{m}$. In the CA1 region, EYFP-labeled INs of SOM-IRES-Cre;Ai3-EYFP mice are present mostly in the oriens and alveus regions, whereas EYFP-labeled INs of PV-Cre;Ai3-EYFP mice are found near or in the pyramidal cell layer. $\boldsymbol{C}, \boldsymbol{D}$, Representative examples of specific colocalization of EYFP-labeled INs (top, green) from SOM-IRESCre;Ai3-EYFP $(\boldsymbol{C})$ and PV-Cre;Ai3-EYFP $(\boldsymbol{D})$ mice with immunofluorescence for somatostatin (middle left, red) and parvalbumin (middle right, red), respectively. Merged images are shown at bottom. Scale bars, $10 \mu \mathrm{m}$. Nearly all CA1 EYFP-labeled INs from SOM-IRESCre;Ai3-EYFP mice colocalized with somatostatin but not parvalbumin $(\boldsymbol{C})$. Conversely, mostly all CA1 EYFP-labeled INs from PV-Cre;Ai3-EYFP mice were immunopositive for parvalbumin but not somatostatin $(\boldsymbol{D})$.

was $24.6 \pm 2.8 \mathrm{~ms}(n=10)$, the action potential half-width and amplitude were $0.44 \pm 0.05 \mathrm{~ms}(n=13)$ and $66.5 \pm$ $2.3 \mathrm{mV}(n=13)$, respectively, the action potential threshold was $-40.4 \pm 1.7 \mathrm{mV}(n=13)$ and the average firing frequency in response to depolarizing pulses was $23.6 \pm$ $2.0 \mathrm{~Hz}$ at $2 \times$ threshold $(n=13)$. The cells also displayed a membrane sag at hyperpolarized membrane potentials $(0.92 \pm 0.01 \mathrm{sag}$ index; $n=9)$. These properties are consistent with those previously reported for SOM-INs identified by mRNA expression (Tricoire et al., 2011).

Then we used whole-cell voltage-clamp recordings of EPSCs evoked by minimal stimulation of putative singlefibers to examine if excitatory synapses onto CA1 EYFP- labeled SOM-INs show Hebbian LTP. Pairing of thetaburst stimulation with postsynaptic depolarization (TBS + Depo) produced an increase in EPSC amplitude (average EPSC including failures) to $202.9 \pm 31.3 \%$ of baseline at 30 min postinduction (paired $t$ test, $p=0.0025^{\mathrm{a}}, n=14$; Fig. $3 A, D$ ). Control stimulation, consisting of theta-burst stimulation $(n=7)$ or depolarization $(n=7)$ alone, did not produce lasting changes in EPSC amplitude (96.0 \pm $11.1 \%$ of baseline at 30 min postinduction for pooled controls; paired $t$ test, $p=0.75^{\mathrm{b}}, n=14$; Fig. $\left.3 B, D\right)$.

When examined in individual cells, LTP occurred in 9 of 14 cells that received the pairing stimulation protocol (TBS + Depo), so the development of LTP over time was 

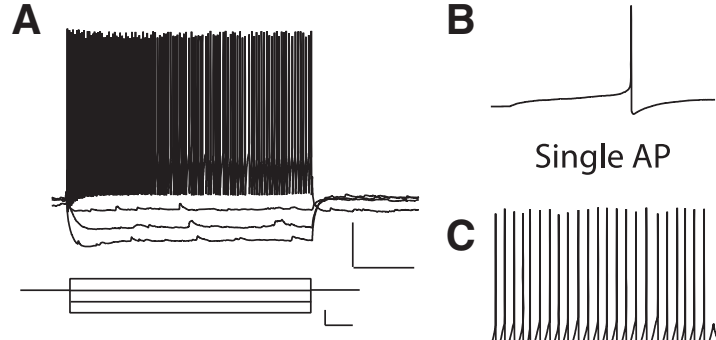

Single AP

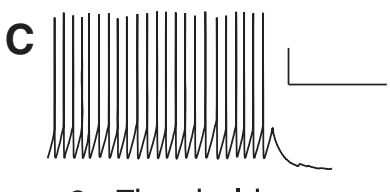

$2 \times$ Threshold

Figure 2. Membrane properties of CA1 EYFP-labeled SOMINs. $\boldsymbol{A}$, Example of voltage responses (top; scale bars: $20 \mathrm{mV}$, $200 \mathrm{~ms}$ ) during current-clamp recordings evoked by current steps (bottom; scale bars: 40 pA, $100 \mathrm{~ms}$ ) of varying amplitude from a representative CA1 EYFP-labeled SOM-IN (held at Vm of $-60 \mathrm{mV}$ ). B, C, Representative examples of traces with single action potential $(\boldsymbol{B})$ and repetitive firing (at $2 \times$ threshold; $\boldsymbol{C}$ ) evoked by current-pulse injections. Scale bars: 20 mV, 200 ms.

analyzed in these cells (Fig. 3E-G). A post-test for linear trend revealed that EPSC amplitude (including failures), potency (EPSC amplitude excluding failures) and failure rate changed gradually over the 5-30 min period after LTP induction (ANOVA, $p<0.0001^{\mathrm{c}}, n=9$ ). EPSC amplitude was increased at $20-25 \mathrm{~min}(203.7 \pm 24.2 \%$ of baseline $)$ and $25-30 \mathrm{~min}$ [207.7 $\pm 25.9 \%$ of baseline; repeatedmeasures $(\mathrm{rm})$ ANOVA, $p=0.0016^{\mathrm{d}}$, and Dunnett's multiple-comparison test, $n=9$; Fig. 3E]. EPSC potency was increased at $20-25 \min (149.7 \pm 14.1 \%$ of baseline) and $25-30 \mathrm{~min}(164.0 \pm 15.3 \%$ of baseline; rmANOVA, $p=0.0025^{\mathrm{e}}$, and Dunnett's multiple-comparison test, $n=$ 9; Fig. 3F). EPSC failure rate was decreased at $15-20 \mathrm{~min}$ ( $77.8 \pm 8.5 \%$ of baseline), $20-25 \min (59.8 \pm 10.4 \%$ of baseline), and $25-30 \mathrm{~min}(62.7 \pm 9.1 \%$ of baseline; rmANOVA, $p=0.011^{\mathrm{f}}$, and Dunnett's multiple-comparison test, $n=9$; Fig. 3G). In cells with control stimulation, there were no significant changes over time in EPSC amplitude $(96.0 \pm 11.1 \%$ of baseline at $30 \mathrm{~min}$; rmANOVA, $p=$ $\left.0.7512^{g} ; n=14\right)$, potency $(100.9 \pm 7.5 \%$ of baseline at 30 min, rmANOVA, $\left.p=0.9456^{h}\right)$ or failure rate $(97.1 \pm 6.3 \%$ of baseline at $30 \mathrm{~min}$, rmANOVA, $p=0.6528^{\mathrm{i}}$; Fig. $3 E-G$ ).

These results show that CA1 SOM-IN excitatory synapses show a gradual late-onset LTP expressed as an increase in EPSC amplitude and potency, as well as a decrease in EPSC failure rate after the Hebbian pairing protocol.

\section{LTP at SOM-IN excitatory synapses depends on mGluR1a}

SOM-INs in CA1 specifically express mGluR1a at high level (Baude et al., 1993; Somogyi and Klausberger, 2005) and Hebbian LTP in oriens-alveus interneurons is dependent on mGluR1a activation (Perez et al., 2001). Therefore, we examined whether LTP in CA1 EYFP-labeled SOM-INs was also mGluR1a dependent, using the mGluR1a antagonist LY 367385. Application of the pairing protocol, TBS, and depolarization, in the presence of LY $367385(40 \mu \mathrm{M})$ failed to produce LTP (Fig. 3C,D). At 30 min postinduction, there were no significant changes in
EPSC amplitude $(78.8 \pm 4.9 \%$ of baseline; rmANOVA, $p=0.0846^{\mathrm{j}}, n=6$; Fig. $\left.3 C-E\right)$, EPSC potency (85.2 \pm $5.7 \%$ of baseline; rmANOVA, $p=0.3121^{\mathrm{k}}, n=6$; Fig. $3 F$ ), and failure rate $(128.7 \pm 11.0 \%$ of baseline; rmANOVA, $p$ $=0.1212^{\prime}, n=6$; Fig. 3G).

\section{Absence of LTP at synapses onto PV-INs}

PV-INs are another distinct subpopulation of interneurons with perisomatic projections to pyramidal cells (Freund and Buzsáki, 1996). Next we used a similar approach but with whole-cell recordings from CA1 EYFP-labeled PVINs obtained from PV-Cre;Ai3-EYFP mice to determine whether Hebbian mGluR1a-mediated LTP was also present in this interneuron type or whether it was cell-type-specific. Pairing of theta-burst stimulation with postsynaptic depolarization (TBS + Depo; Fig. 4A,C) failed to produce gradual changes in EPSC amplitude in CA1 EYFP-labeled PV-INs over 30 min postinduction (average EPSC including failures: $67.8 \pm 15.4 \%$ of baseline at $30 \mathrm{~min}$ postinduction; paired $t$ test, $p=0.2057^{\mathrm{m}} ; n=6$; Fig. $4 D$ ). Similarly, control stimulation, consisting of theta-burst stimulation $(n=4)$ or depolarization $(n=2)$ alone (Fig. 4B,C), did not produce lasting changes in EPSC amplitude $(119.0 \pm 33.6 \%$ of baseline at 30 min postinduction for pooled controls; paired $t$ test, $p=$ $0.6333^{n} ; n=6$; Fig. $4 D$ ). These results reveal that Hebbian mGluR1a-mediated LTP is absent from afferent inputs to another large population of CA1 interneurons, the PV-INs, and thus shows cell-type specificity for SOM-INs synapses.

\section{Facilitation of CA1 Schaffer collateral pathway LTP by TBS in oriens-alveus}

Next we investigated the potential role of Hebbian LTP at SOM-IN synapses in the function of the CA1 local circuitry. Activation of dendrite-targeting OLM interneurons, a major subgroup of SOM-INs, differentially regulates LTP at major inputs to CA1 pyramidal cells, reducing LTP in the temporo-ammonic pathway from entorhinal cortex and facilitating LTP in the Schaffer collateral pathway from CA3 (Leão et al., 2012). It has been previously shown that TBS in oriens-alveus, via Hebbian LTP at interneuron input synapses, resulted in long-term enhancement of evoked firing in oriens-alveus interneurons during cellattached recordings (Croce et al., 2010), as well as longterm enhancement of polysynaptic inhibition of pyramidal cells (Lapointe et al., 2004). Therefore, we tested if TBS in oriens-alveus could produce mGluR1a-mediated Hebbian LTP at SOM-IN synapses and result in a long-term regulation of LTP in CA1 Schaffer collateral pathway using field recordings. First we established, using whole-cell current clamp recordings from SOM-IRES-Cre;Ai3-EYFP mice, that TBS in oriens-alveus induces LTP of excitatory synapses onto SOM-IN in the same conditions used for field recordings (bulk stimulating electrode, absence of postsynaptic depolarization, absence of glutamatergic and GABAergic antagonists, see Materials and Methods). In these conditions, TBS in oriens-alveus produced a gradual increase (linear regression, ANOVA, $p<0.001^{\circ}, n=8$ ) in EPSP amplitude (average EPSP including failures) reaching $187.8 \pm$ $10.6 \%$ of baseline at 30 min postinduction (rmANOVA, $p<$ $0.001^{\mathrm{p}}$, and Dunnett's multiple-comparison tests, $n=8$; Fig. $5 A, D)$. Bath application of $40 \mu \mathrm{M}$ LY367385 decreased the 
A

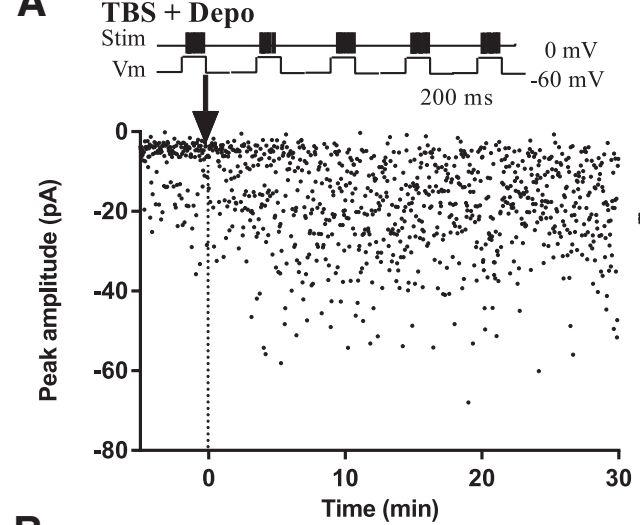

B
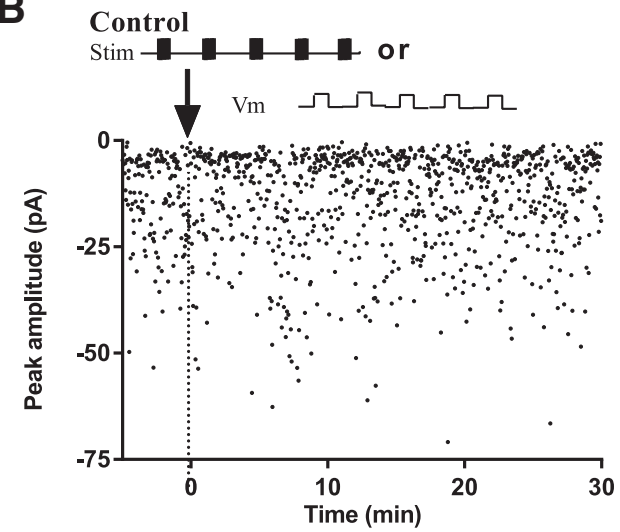

C
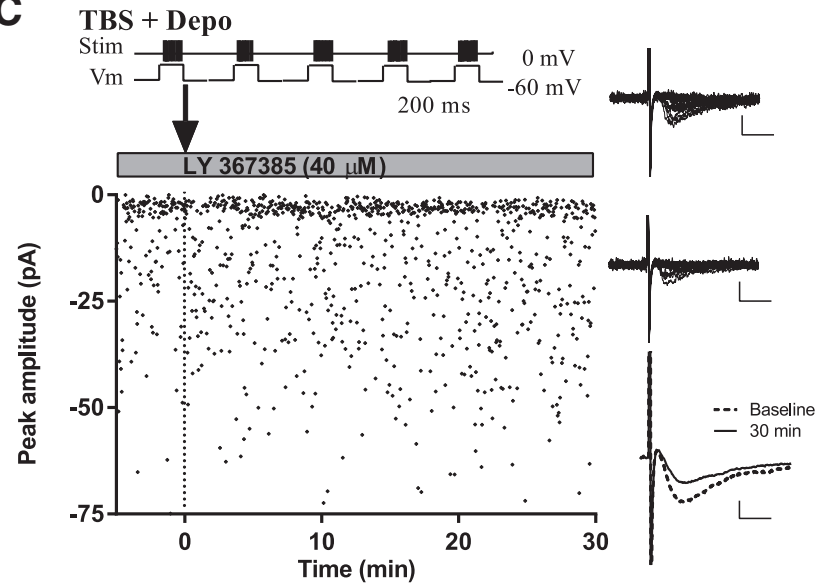

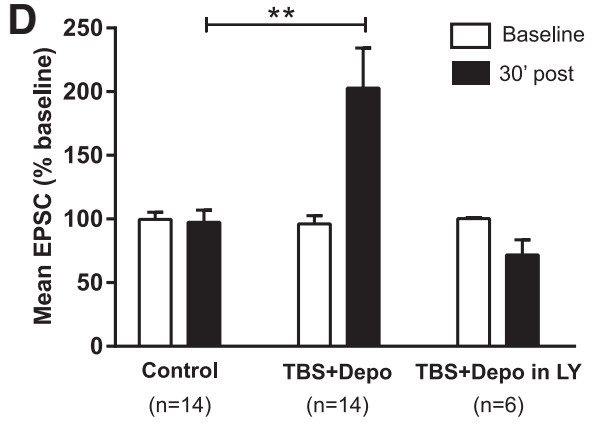

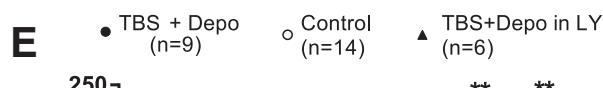
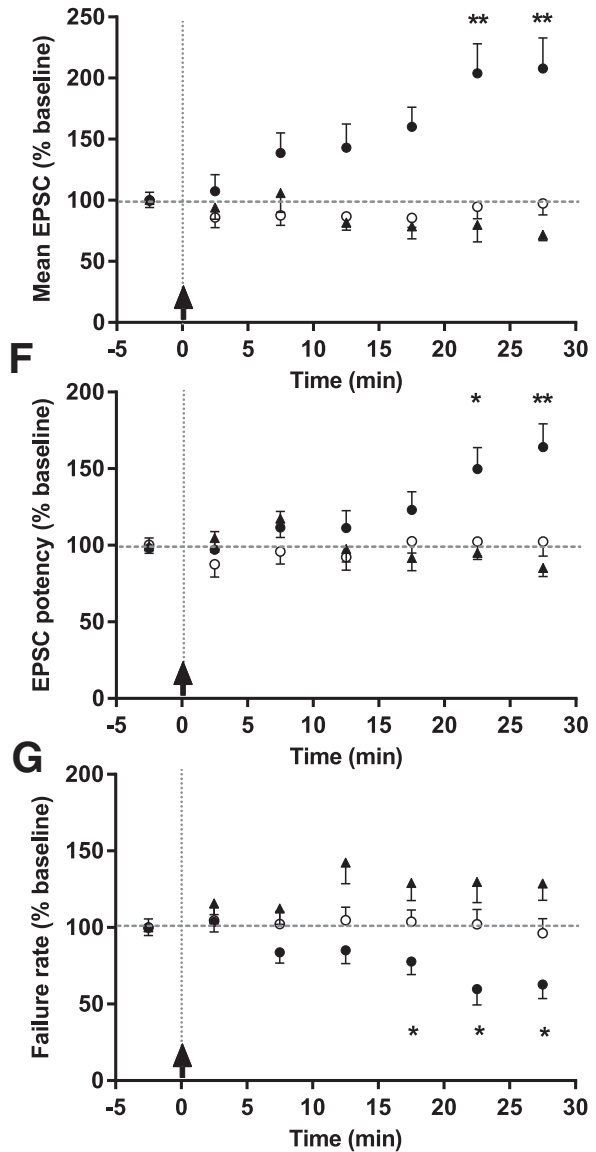

Figure 3. mGluR1a-dependent Hebbian LTP at excitatory synapses onto CA1 EYFP-labeled SOM-INs. A-C, Diagrams (top, left) showing the stimulation pairing protocol for LTP induction ( $\boldsymbol{A}$; theta-burst stimulation paired with postsynaptic depolarization; TBS + Depo), the control stimulation protocols ( $\boldsymbol{B}$; TBS or postsynaptic depolarization alone) and the stimulation pairing protocol in the presence of $40 \mu \mathrm{M}$ LY367385, an mGluR1a antagonist (C; TBS + Depo in LY). EPSC amplitude time plots (bottom, left) from representative CA1 EYFP-labeled SOM-INs showing increase in EPSC amplitude after the pairing protocol (A) but not after control stimulation (B; TBS alone in this particular example) nor in the presence of LY367385 (C). Twenty consecutive EPSC traces from respective cells from baseline period (top, right) and $30 \mathrm{~min}$ poststimulation (middle, right). Scale bars: $20 \mathrm{pA}, 5 \mathrm{~ms}$. Superimposed average traces (of 100 individual events, including failures; bottom, right; scale bars: 5 pA, $5 \mathrm{~ms}$ ) illustrating the increase in response after the pairing protocol $(\boldsymbol{A})$ but not control stimulation $(\boldsymbol{B})$ nor in the presence of LY367385 $(\boldsymbol{C})$. $\boldsymbol{D}$, Summary bar graph for all cells, showing no change in EPSC amplitude (including failures) after control stimulation, increase 30 min after the pairing protocol, and no change after the pairing protocol in the presence of LY367385. ANOVA, $* * p=0.0025$. $E$ - $\boldsymbol{G}$, Summary time plots of EPSC measures (5 min bins) showing gradual development of LTP over time in all cells showing LTP after pairing $(n=9)$, but not in cells with control stimulation $(n=14)$ nor in cells with the pairing stimulation in the presence of LY367385 $(n=6)$. LTP was manifested as an increase in EPSC amplitude (including failures; $\boldsymbol{E}$ ) and potency $(\boldsymbol{F})$, and a decrease in failure rate $(\boldsymbol{G})$. ANOVA and Dunnett's multiplecomparison tests; $* p<0.05, * * p<0.01$. 
A

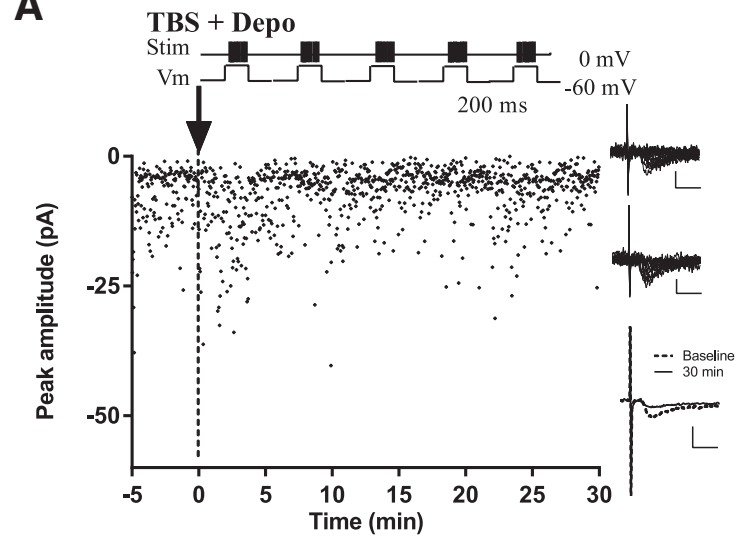

C

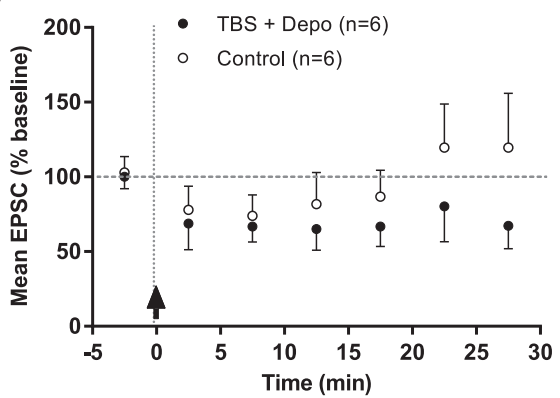

B
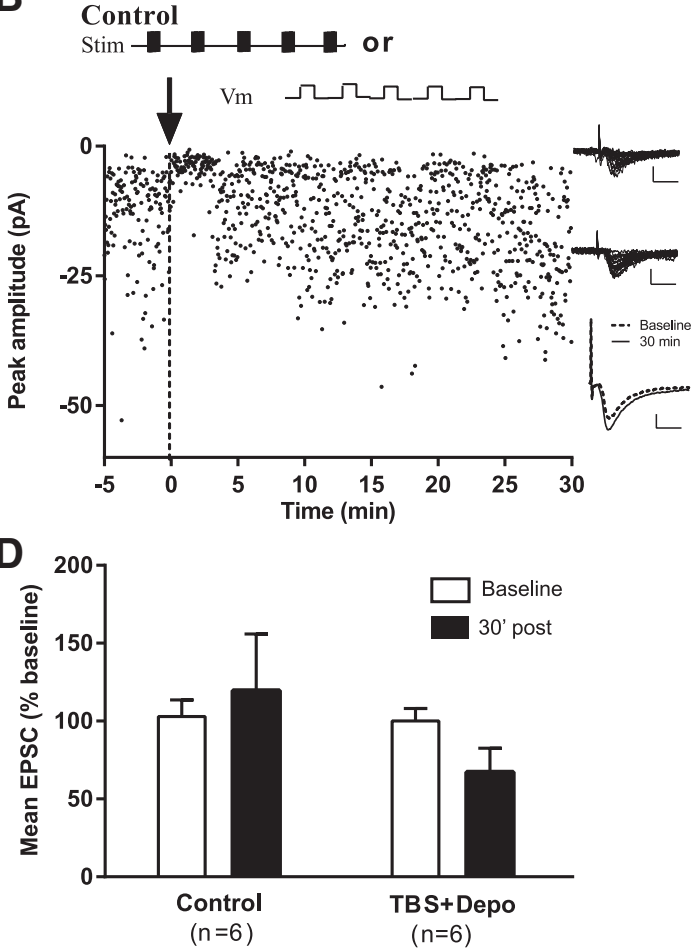

Figure 4. Absence of LTP at the excitatory synapses onto CA1 EYFP-labeled PV-INs. A, B, Diagrams (top) showing the pairing protocol for LTP induction (A; theta-burst stimulation paired with postsynaptic depolarization; TBS + Depo) and the control stimulation protocols ( $\boldsymbol{B}$; TBS or postsynaptic depolarization alone). EPSC amplitude time plots (bottom, left) from representative CA1 EYFP-labeled PV-INs showing no increase in EPSC amplitude after the pairing protocol $(\boldsymbol{A})$ nor after control stimulation (B; TBS alone in this example). Twenty individual traces from respective cells during baseline period (top, right) and 30 min poststimulation (middle, right). Scale bars: $10 \mathrm{pA}, 5 \mathrm{~ms}$. Superimposed average traces (of 100 individual events, including failures; bottom, right; scale bars: $5 \mathrm{pA}, 5 \mathrm{~ms}$ ) illustrating the failure to increase responses after the pairing protocol $(\boldsymbol{A})$ or control stimulation $(\boldsymbol{B})$. $\boldsymbol{C}$, Summary time plots of EPSC amplitude (5 min bins) for all cells showing no change over time in EPSC amplitude (including failures) after the pairing protocol $(n=6)$ or control stimulation $(n=6)$. ANOVA and Dunnett's multiple-comparison tests, $p>0.05$. $\boldsymbol{D}$, Summary bar graphs for all cells showing lack of LTP in PV-INs after the pairing protocol $(n=6$; ANOVA, $p=0.205)$ or control stimulation $(n=6 ; p=0.633)$.

number of action potentials elicited during the TBS protocol (without LY, $48.6 \pm 2.7$ action potentials, $n=8$; with LY, 26.8 \pm 6.9 action potentials, $n=5$; Student's test, $p=0.005^{9}$; Fig. $5 A-C)$ and prevented TBS-induced LTP of EPSP amplitude. After TBS in oriens-alveus in the presence of LY367385, EPSP amplitude was $78 \pm 5.4 \%$ of baseline at 30 min postinduction (rmANOVA, $p=0.0007^{r}$, and Dunnett's multiple-comparison tests, $n=5$; Fig. $5 B, D$ ). These results demonstrate that mGluR1a-mediated LTP at excitatory synapses onto SOM-INs occurs in conditions for field potential recordings of LTP in the Schaffer collateral pathway.

We then investigated whether LTP at SOM-INs synapses could produce a long-term regulation of LTP in the Schaffer collateral pathway using field recordings. In addition, for these experiments we used SOM-IRES-Cre; ArChR3/GFP mice for cell-specific expression in SOMINs of archaerhodopsin-3 (ArCh3), an outward proton pump that causes hyperpolarization, so we could manipulate selectively SOM-IN excitability using optogenetics during field recording experiments. First, low-frequency Schaffer collateral stimulation was given in stratum radiatum to elicit CA1 fEPSPs during a baseline period (30 min; Fig. $6 A, B)$. HFS (100 Hz, $1 \mathrm{~s})$ of Schaffer collaterals was then applied, resulting in LTP of fEPSP slope (113.5 \pm $4.7 \%$ of baseline at 30 min postinduction; $n=10$, paired $t$ test, $p=0.010^{\text {s; }}$ Fig. $\left.6 B, E, F\right)$. In comparison, application of TBS in oriens-alveus resulted in enhancement of Schaffer collateral pathway LTP tested 30 min later (Fig. 6A,C). TBS in oriens-alveus did not affect Schaffer collateral evoked fEPSPs during the baseline period, indicating no effect on basal transmission (Fig. 6D). However, LTP induction in the Schaffer collateral pathway given $30 \mathrm{~min}$ after TBS in oriens-alveus, resulted in an increase in fEPSP slope (128.2 $\pm 3.5 \%$ of baseline, $n=11$; paired $t$ test, $p=0.0001^{\text {t }}$; Fig. $6 C, E$ ) that was greater than in the control condition without TBS (ANOVA, $p=0.0052^{\mathrm{u}}$; Fig. $6 F$ ). The effect of TBS in oriens-alveus was tested also on Schaffer collateral pathway for the same time period but without subsequent LTP induction. TBS in oriens-alveus had no effect on Schaffer collateral fEPSPs recorded for a similar duration (102.2 $\pm 2.6 \%$ of baseline; $n=4$; paired $t$ test, $p=0.5794^{\mathrm{v}}$; Fig. $\left.6 D-F\right)$. These results indicate that TBS in oriens-alveus does not affect basal transmission at CA3-CA1 synapses, but has a long-lasting effect to enhance LTP in the Schaffer collateral pathway. 
A
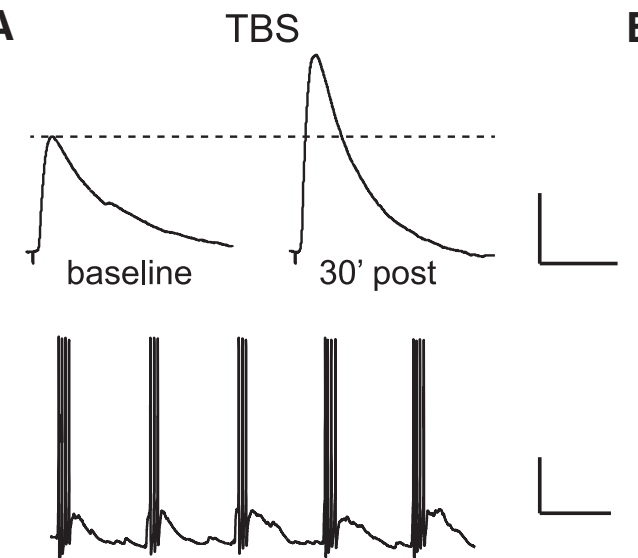

B
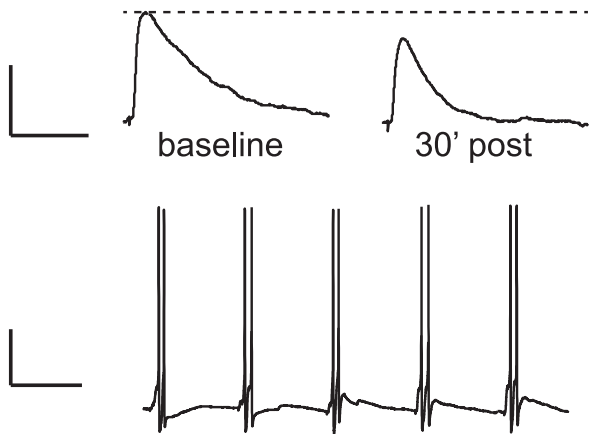

C

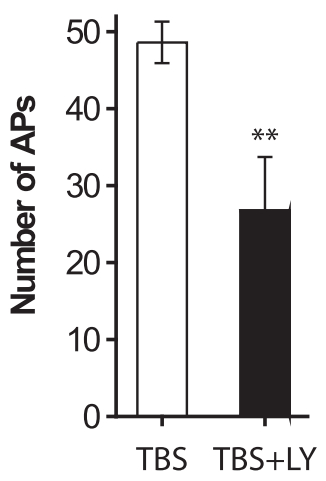

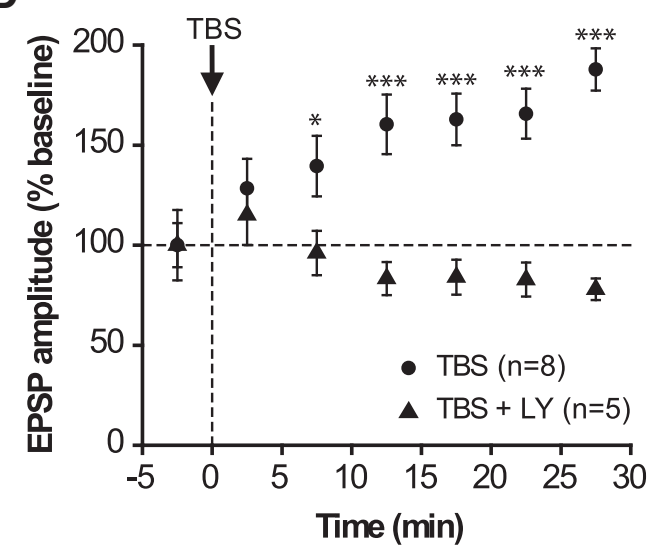

Figure 5. mGluR1a-dependent LTP in current-clamp recordings with intact glutamatergic and GABAergic transmission. $A$, $B$, Averaged EPSPs from 30 consecutive responses during the baseline period (top, left) and 30 min after TBS (top, right) in the absence $(\boldsymbol{A})$ and presence $(\boldsymbol{B})$ of LY367385 from representative EYFP-labeled SOM-INs. Firing patterns during TBS (bottom). Note the prolonged depolarization underlying each burst in control conditions $(\boldsymbol{A})$, which is abolished in the presence of LY367385 $(\boldsymbol{B})$. Scale bars: top, $2 \mathrm{mV}, 50 \mathrm{~ms}$; bottom, $20 \mathrm{mV}, 200 \mathrm{~ms}$. C, Bar graph showing the decreased number of APs elicited during the TBS protocol in the absence $(n=8)$ and presence $(n=5)$ of LY367385 (Student's test). $\boldsymbol{D}$, Summary time plot of EPSP amplitude (5 min bins) for all cells, showing the gradual development of LTP over time, which is blocked in the presence of LY367385 (rmANOVA, $p=0.001$, and Dunnett's multiple-comparison tests from baseline). $* p<0.05, * * p<0.01, * * * p<0.001$

\section{TBS-induced enhancement of Schaffer collateral LTP is mediated by SOM-INs}

The observed TBS-induced enhancement of Schaffer collateral pathway LTP is consistent with TBS inducing mGluR1a-mediated Hebbian LTP at SOM-INs synapses, and resulting in increased SOM-IN facilitation of LTP in the Schaffer collateral pathway from CA3 (Leão et al., 2012).

We next investigated whether the TBS-induced enhancement of CA1 Schaffer collateral pathway LTP was dependent on SOM-INs in SOM-IRES-Cre;ArChR3/GFP mice using optogenetics to selectively hyperpolarize SOM-INs during TBS. In control whole-cell recordings from GFP-expressing SOM-INs in slices from SOM-IRESCre;ArChR3/GFP mice, yellow light (591 nm wavelength) illumination of the slice through an optic fiber induced membrane hyperpolarization for the duration of light stimulation (Fig. $7 A ; 1.5 \mathrm{~s}, n=5$ cells).

Next we examined the TBS-induced modulation of Schaffer collateral pathway LTP in the presence of yellow light stimulation. First as control, we verified that prior application of light alone (1.5 min duration) did not affect Schaffer collateral pathway LTP (Fig. 7B). In these conditions, illumination did not affect fEPSPs during the baseline period and HFS caused an increase in fEPSPs slope $(112.7 \pm 1.5 \%$ of baseline at $30 \mathrm{~min}$ postinduction; $n=9$; paired $t$ test, $p=0.0001^{\mathrm{w}}$; Fig. $\left.7 E, F\right)$ similar to previous results testing HFS alone (Fig. 7F). Interestingly, TBS in oriens-alveus given during light stimulation did not affect fEPSPs during the baseline period, but failed to enhance HFS-induced LTP (Fig. 7C). HFS given 30 min after TBS in oriens-alveus during light stimulation, resulted in an increase in fEPSP slope $(110.1 \pm 2.3 \%$ of baseline at 30 min postinduction; $n=7$; paired $t$ test, $p=0.0030^{\times}$; Fig. $7 E, F)$ that was not different from that without TBS (ANOVA, $p=0.0751^{\mathrm{y}}$; Fig. $7 F$ ). Light stimulation alone had no effect on Schaffer collateral fEPSPs recorded for a similar period (103.6 $\pm 1.1 \%$ of baseline; paired $t$ test, $\mathrm{p}=0.0690^{z} ; n=3$; Fig. 7D-F). These results indicate that TBS-induced enhancement of Schaffer collateral pathway 


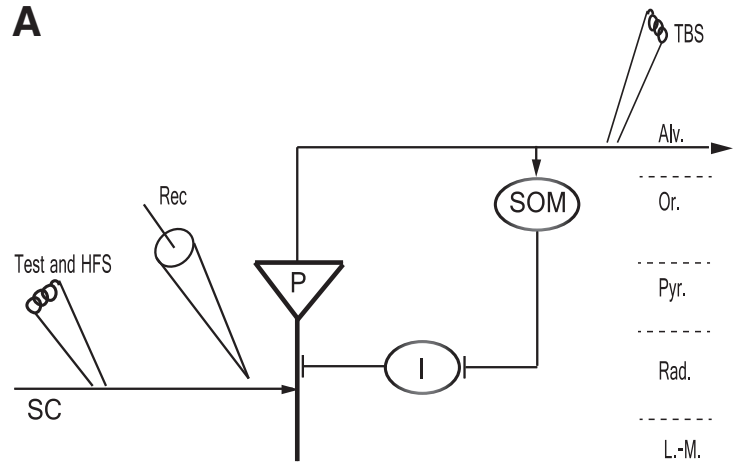

B

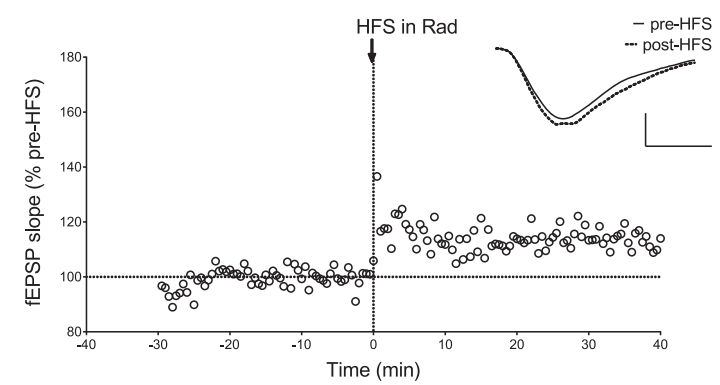

C

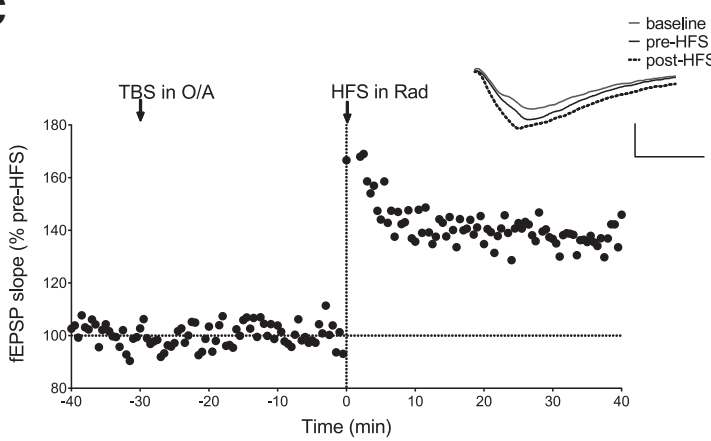

D

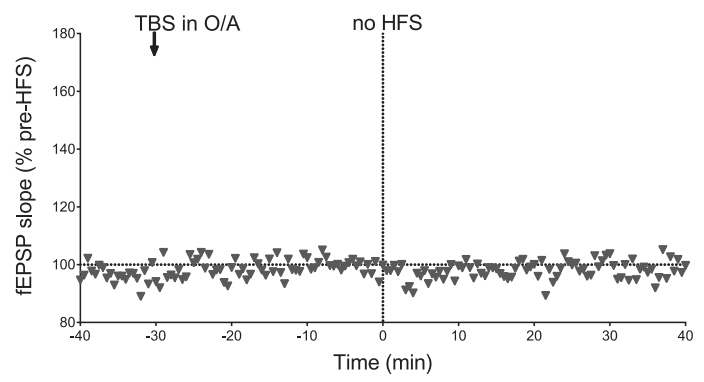

E

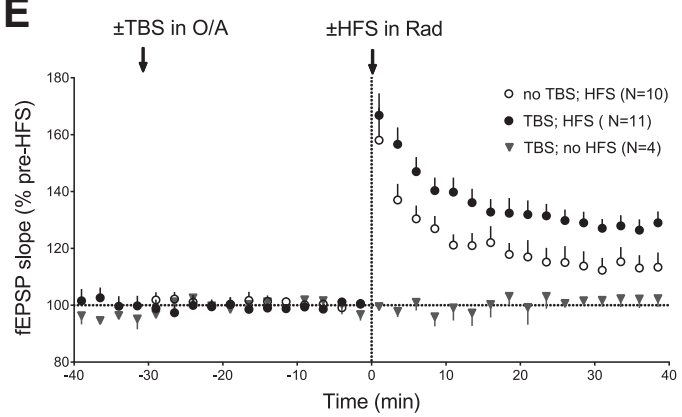

$F$

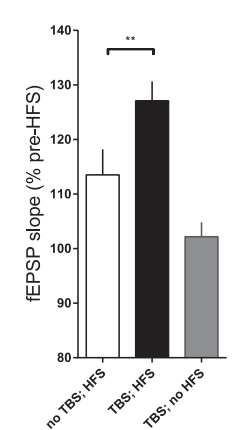

Figure 6. Regulation of Schaffer collateral pathway LTP by theta-burst stimulation in oriens-alveus. $\boldsymbol{A}$. Diagram of experimental arrangement of extracellular recording and stimulation electrodes, and targeted CA1 pathways and cells. P, Pyramidal cell; I, inhibitory interneuron; SC, Schaffer collateral pathway; Rec, recording electrode; Alv, alveus; Or, stratum oriens; Pyr, stratum pyramidale; Rad, stratum radiatum; L-M, stratum lacunosum/moleculare. Arrowheads and bars refer to excitatory and inhibitory synapses, respectively. B-D, Time plots of Schaffer collateral fEPSP slope from individual representative slices from SOM-IRES-Cre;ArChR3/GFP mice showing LTP induced by HFS in stratum radiatum $(\boldsymbol{B})$, enhanced LTP when HFS induction was preceded by a conditioning TBS in stratum oriens-alveus 30 min earlier $(\boldsymbol{C})$, and no effect of TBS alone $(\boldsymbol{D})$. Insets $(\boldsymbol{B}, \boldsymbol{C})$ are average fEPSPS (of 30 individual traces) during baseline, pre-HFS, and $30 \mathrm{~min}$ post-HFS. Scale bars: $0.5 \mathrm{mV}, 5 \mathrm{~ms}$. $\boldsymbol{E}$, Summary fEPSP slope time plots for all slices, showing larger magnitude of HFS-induced LTP when preceded by TBS in stratum oriens-alveus. $\boldsymbol{F}$, Summary bar graph showing increased HFS-induced LTP of fEPSP slope at 30 min postinduction after a conditioning TBS in oriens-alveus (TBS; HFS) relative to control without TBS (no TBS; HFS, ANOVA, $* * p=0.0052$ ), and no effects of TBS on fEPSPs in experiments without HFS.

LTP is prevented when TBS is given during light-activated hyperpolarization of SOM-INs, suggesting that SOM-INs activation during TBS is required for TBS-induced enhancement of Schaffer collateral LTP.

\section{TBS-induced enhancement of Schaffer collateral LTP is mGluR1a-dependent}

The impairment of TBS-induced enhancement of Schaffer collateral pathway LTP by light inactivation of SOM-INs during TBS provides further support that TBS may be inducing mGluR1a-mediated Hebbian LTP at SOM-INs synapses to result in increased SOM-IN facilitation of LTP in the Schaffer collateral pathway from CA3. Therefore we next investigated if TBS-induced enhancement of CA1 Schaffer collateral pathway LTP required activation of mGluR1a, using the mGluR1a antagonist LY367385, which blocks LTP in SOM-INs (Figs. 3, 5).

Application of LY367385 did not affect Schaffer collateral pathway LTP (Fig. 8A). In the presence of LY367385, HFS caused an increase in fEPSPs slope $(112.2 \pm 4.5 \%$ of baseline at 30 min postinduction; $n=8$; paired $t$ test, $p$ $=0.0050^{\text {aa}}$; Fig. $8 D, E$ ) similar to previously found with HFS alone (Fig. $8 E$ ). Importantly, TBS in oriens-alveus in 
A
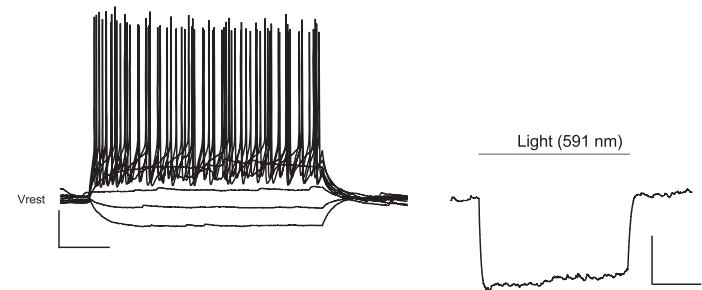

B

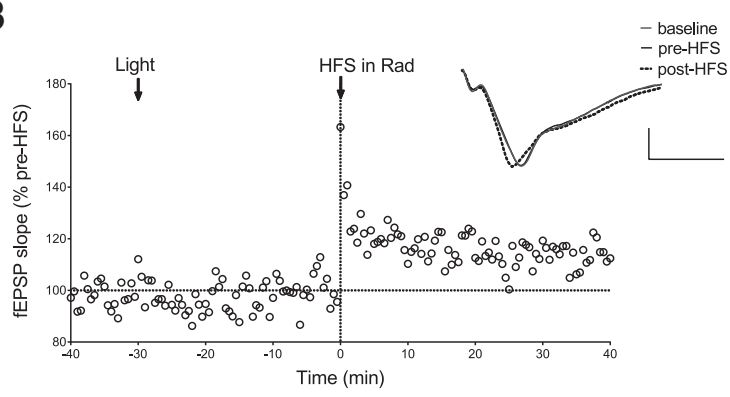

C

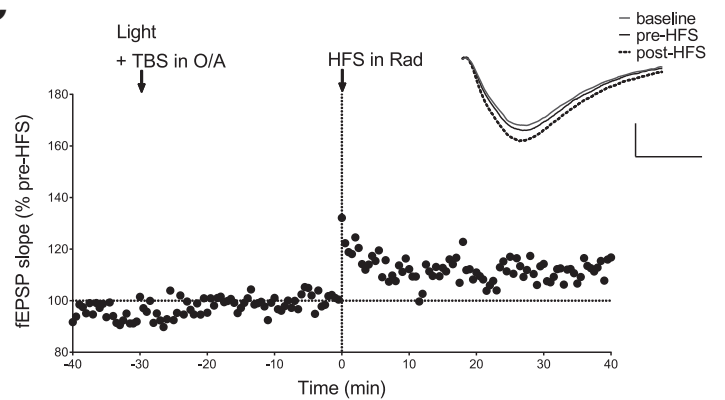

D

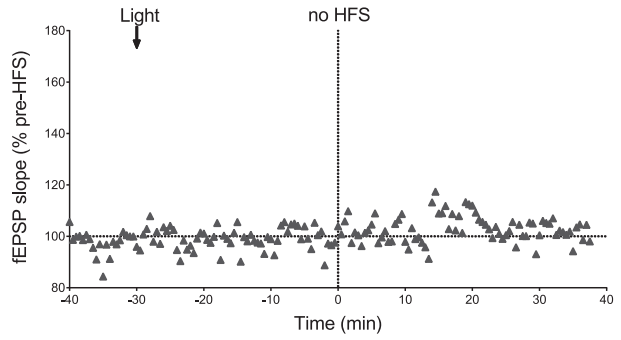

E

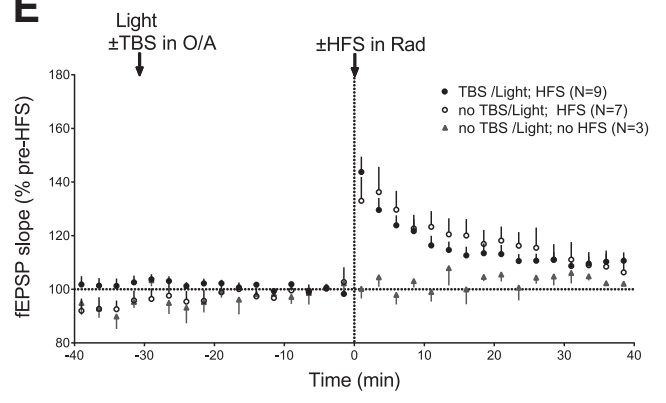

F

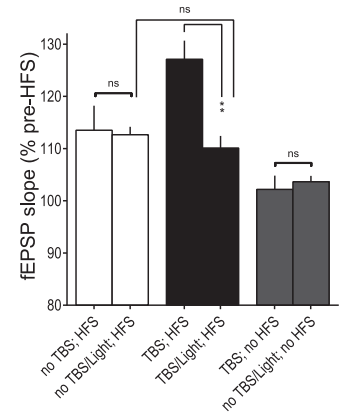

Figure 7. TBS-induced enhancement of Schaffer collateral pathway LTP is prevented by SOM-INs hyperpolarization. $A$, Whole-cell current-clamp recordings from a representative GFP-expressing SOM-IN in acute slice of SOM-IRES-Cre;ArChR3/GFP mouse, showing responses to current step injections (left) and membrane hyperpolarization in response to wide-field yellow light (591 $\mathrm{nm}$ ) exposition (right). Scale bars: left, $20 \mathrm{mV}, 100 \mathrm{~ms}$; right, $10 \mathrm{mV}, 500 \mathrm{~ms}$. $\boldsymbol{B}-\boldsymbol{D}$, Time plots of Schaffer collateral fEPSP slope from representative slices from SOM-IRES-Cre;ArChR3/GFP mice showing similar LTP induced by HFS in stratum radiatum when preceded by yellow light exposition 30 min earlier $(\boldsymbol{B})$ and by conditioning TBS in stratum oriens-alveus during yellow light exposition $(\boldsymbol{C})$, and no effect of yellow light exposition alone on fEPSPs $(\boldsymbol{D})$. Insets $(\boldsymbol{B}, \boldsymbol{C})$ are average fEPSPs (of 30 individual traces) from baseline, pre-HFS, and $30 \mathrm{~min}$ post-HFS. Scale bars: $0.5 \mathrm{mV}, 5 \mathrm{~ms}$. $\boldsymbol{E}$, Summary fEPSP slope time plots for all slices, showing no enhancement of HFS-induced LTP when TBS in stratum oriens-alveus is given during yellow light exposition. $\boldsymbol{F}$, Summary bar graph showing similar HFS-induced LTP of fEPSP slope at 30 min postinduction after a conditioning TBS in oriens-alveus with versus without yellow light exposition (ANOVA, $p=0.0751$; n.s.), and no effects of light alone on fEPSPs in experiments without HFS.

the presence of the mGluR1a antagonist LY367385 failed to enhance HFS-induced LTP (Fig. 8B). HFS given 30 min after TBS in LY367385 resulted in an increase in fEPSP slope $(116.0 \pm 3.0 \%$ of baseline at 30 min postinduction;

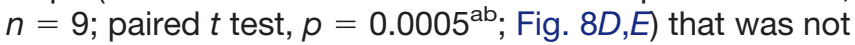
different from that without TBS (ANOVA followed by Dunnett's multiple-comparison test, $p>0.05$; Fig. 8E). Application of LY367385 alone had no effect on Schaffer collateral fEPSPs recorded for a similar period (97.6 \pm $9.0 \%$ of baseline; paired $t$ test, $p=0.4856^{\mathrm{ac}} ; n=4$; Fig. $8 C-E$ ). These results indicate that mGluR1a activation during TBS is required for TBS-induced enhancement of Schaffer collateral LTP.

Collectively, these series of experiments show that TBS-induced enhancement of Schaffer collateral pathway LTP is prevented by light inactivation of SOM-INs and by
mGluR1a antagonism (Figs, 7, 8), suggesting TBS in oriens-alveus produces mGluR1a-mediated Hebbian LTP at SOM-INs synapses and results in a long-term upregulation of LTP in CA1 Schaffer collateral pathway (Table 1).

\section{Discussion}

In the present study, we have demonstrated a Hebbian form of LTP occurring at excitatory synapses onto identified SOM-INs in the hippocampal CA1 area. This form of LTP was dependent on mGluR1a and did not occur in PV-INs. In addition, our results revealed that prior induction of mGluR1a-dependent LTP in SOM-INs enhanced the magnitude of LTP at SC synapses in pyramidal cells. These results uncover a novel metaplastic function of O/A SOM-INs conferring to them the ability to modulate durably CA1 network activity and plasticity. 
A

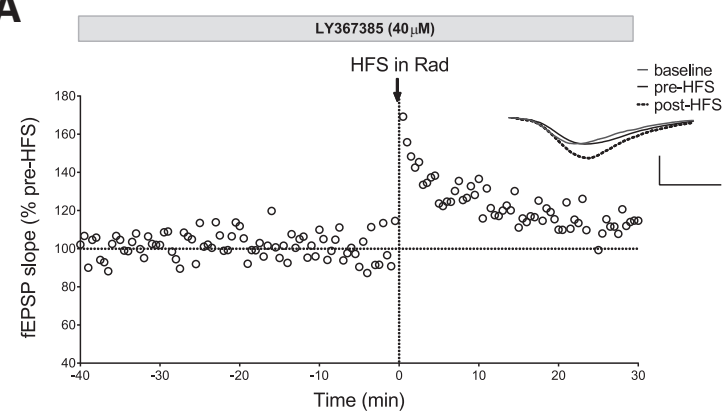

B

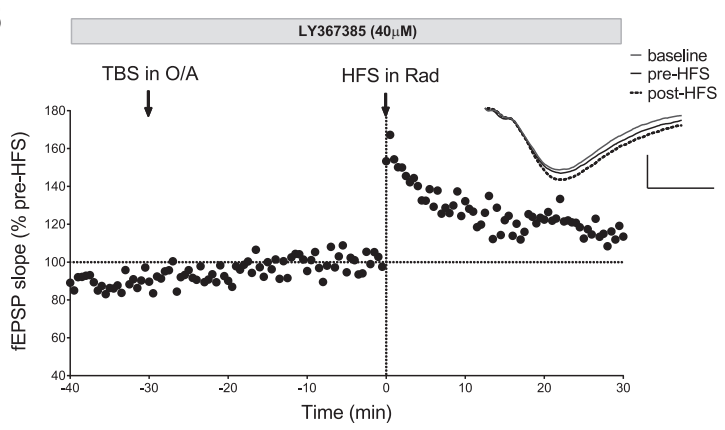

C

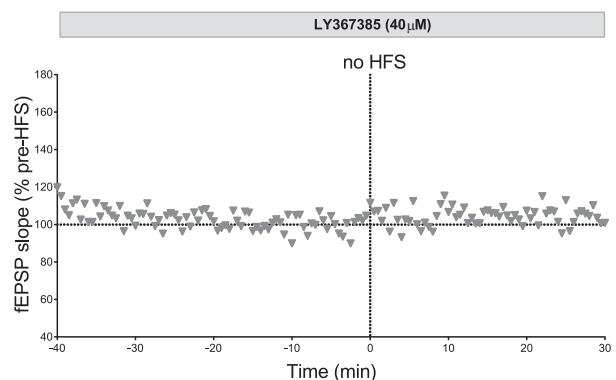

D

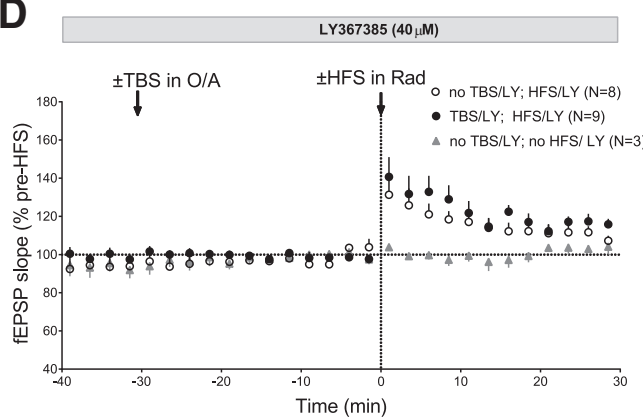

E

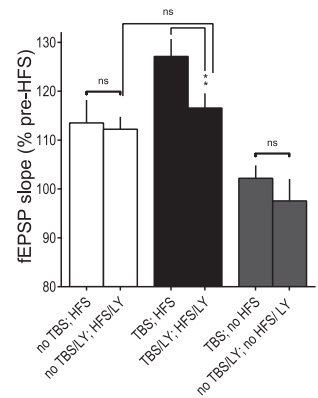

Figure 8. TBS-induced enhancement of Schaffer collateral pathway LTP is prevented by mGluR1a blockade. A-C, Time plots of Schaffer collateral fEPSP slope from representative slices from SOM-IRES-Cre;ArChR3/GFP mice showing that, in the presence of the mGluR1a antagonist LY367385, LTP induced by HFS in stratum radiatum $(\boldsymbol{A})$ is similar to LTP induced by HFS which is preceded by conditioning TBS in stratum oriens-alveus 30 min earlier $(\boldsymbol{B})$, and that fEPSPs are unaffected during long-term recordings in the presence of LY367385 $(\boldsymbol{C})$. Insets $(\boldsymbol{A}, \boldsymbol{B})$ are average fEPSPs (of 30 individual traces) from baseline, pre-HFS, and 30 min post-HFS. Scale bars: $0.5 \mathrm{mV}, 5 \mathrm{~ms}$. $\boldsymbol{D}$. Summary fEPSP slope time plots for all slices, showing no enhancement of HFS-induced LTP when TBS in stratum oriens-alveus is given in the presence of LY367385. $\boldsymbol{E}$, Summary bar graph showing similar HFS-induced LTP of fEPSP slope at 30 min postinduction whether preceded or not by a conditioning TBS in oriens-alveus in the presence of LY367385 (ANOVA followed by Dunnett's multiple-comparison test, $p>0.05$ ), lack of TBS-induced enhancement of Schaffer collateral pathway LTP in the presence of LY367385 (ANOVA, $* * p=0.0052$ ) and no effects of LY367385 alone on fEPSPs in experiments without HFS.

\section{mGluR1a Hebbian LTP at excitatory feedback synapses onto SOM-INs}

The large diversity of interneurons within the cerebral cortex has been a major hurdle for the detailed investigation of the function of synaptic plasticity in various interneurons. The emergence and development of Cre-lox system for recombination of reporter genes has made possible to target selectively interneuron classes by taking advantage of their specific pattern of protein expression. This approach allowed us to visualize and target two major, mainly nonoverlapping, classes of hippocampal CA1 interneurons: (1) the dendrite-targeting SOM-INs of the O/A region, corresponding largely to the OLM and bistratified cells; and (2) the perisomatic projecting PV-INs located within and nearby the pyramidal layer, corresponding mainly to the basket and axoaxonic cells (for review, see Freund and Buzsáki, 1996; Klausberger and Somogyi, 2008; Tricoire et al., 2011). We demonstrated that TBS episodes delivered to the O/A region, to stimulate CA1 pyramidal cell axon collateral excitatory inputs, induce LTP in O/A SOM-INs but not in PV-INs. This result extends the interneuron subtype specificity of LTP that has been previously described in the heterogeneous interneuron population of the O/A region (Perez et al., 2001; Lapointe et al., 2004; Croce et al., 2010).

As previously demonstrated, this type of LTP was induced in O/A SOM-INs by pairing presynaptic theta-burst stimulation in the O/A region and postsynaptic depolarization, and was dependent on mGluR1a (Perez et al., 2001; Lapointe et al., 2004). Independent on NMDARs, this form of LTP has been called mGluR1a Hebbian LTP, in contrast to the canonical Hebbian NMDAR-dependent 
Table 1. Statistical table

\begin{tabular}{|c|c|c|c|}
\hline & Data structure & Type of test & Power \\
\hline a & Normal distribution & paired $t$ test & 0.0025 \\
\hline$b$ & Normal distribution & paired $t$ test & 0.75 \\
\hline C & Normal distribution & ANOVA & 0.0001 \\
\hline$d$ & Normal distribution & rmANOVA, Dunnett's post hoc & 0.0016 \\
\hline e & Normal distribution & rmANOVA, Dunnett's post hoc & 0.0025 \\
\hline$f$ & Normal distribution & rmANOVA, Dunnett's post hoc & 0.011 \\
\hline g & Normal distribution & rmANOVA & 0.7512 \\
\hline $\mathrm{h}$ & Normal distribution & rmANOVA & 0.9456 \\
\hline $\mathrm{i}$ & Normal distribution & rmANOVA & 0.6528 \\
\hline j & Normal distribution & rmANOVA & 0.0846 \\
\hline $\mathrm{k}$ & Normal distribution & rmANOVA & 0.3121 \\
\hline I & Normal distribution & rmANOVA & 0.1212 \\
\hline $\mathrm{m}$ & Normal distribution & paired $t$ test & 0.2057 \\
\hline $\mathrm{n}$ & Normal distribution & paired $t$ test & 0.6333 \\
\hline o & Normal distribution & ANOVA & 0.0005 \\
\hline $\mathrm{p}$ & Normal distribution & rmANOVA, Dunnett's post hoc & 2.66E-7 \\
\hline$q$ & Normal distribution & $t$ test & 0.0053 \\
\hline r & Normal distribution & rmANOVA, Dunnett's post hoc & 0.0007 \\
\hline S & Normal distribution & paired $t$ test & 0.01 \\
\hline $\mathrm{t}$ & Normal distribution & paired $t$ test & 0.0001 \\
\hline $\mathrm{u}$ & Normal distribution & paired $t$ test & 0.0052 \\
\hline $\mathrm{V}$ & Normal distribution & paired $t$ test & 0.5794 \\
\hline W & Normal distribution & paired $t$ test & 0.0001 \\
\hline$x$ & Normal distribution & paired $t$ test & 0.003 \\
\hline $\mathrm{y}$ & Normal distribution & rmANOVA, Dunnett's post hoc & 0.0751 \\
\hline Z & Normal distribution & paired $t$ test & 0.069 \\
\hline aa & Normal distribution & paired $t$ test & 0.005 \\
\hline $\mathrm{ab}$ & Normal distribution & paired $t$ test & 0.0005 \\
\hline ac & Normal distribution & paired $t$ test & 0.4856 \\
\hline
\end{tabular}

LTP (Ouardouz and Lacaille, 1995; Lamsa et al., 2005) and to the anti-Hebbian CP-AMPAR-dependent LTP requiring postsynaptic hyperpolarization (Lamsa et al., 2007). These three distinct types of LTP occur at excitatory feedback synapses from CA1 pyramidal cells onto interneurons in the O/A region (for review, see Pelletier and Lacaille, 2008; Kullmann et al., 2012; Topolnik, 2012). PV-INs also receive such feedback excitation and it has been reported recently that these synapses display both canonical Hebbian and anti-Hebbian LTP (Le Roux et al., 2013). However, we show here that brief theta-burst stimulation episodes failed to induce Hebbian LTP at excitatory feedback synapses onto PV-INs, probably because this class of interneurons mainly expresses mGluR5 rather than mGluR1 (van Hooft et al., 2000). Our findings thus reveal that theta-burst stimulation induces cell-typespecific mGluR1a-mediated Hebbian plasticity at the excitatory inputs onto SOM-INs, but not PV-INs.

We observed mGluR1a Hebbian LTP in approximately $65 \%$ of the synaptic connections tested in SOM-INs with minimal stimulation and voltage clamp recordings, consistently with previous findings (Lapointe et al., 2004). This may be due to the fact that, in addition to the predominant feedback pathway, the O/A region also contains fibers from CA2/3 pyramidal cells (Ishizuka et al., 1990; BlascoIbáñez and Freund, 1995; Wittner et al., 2007) providing feedforward excitation to O/A-INs through Cl-AMPARs and these synapses do not display mGluR1a Hebbian LTP (Croce et al., 2010), indicating a dual regulation of synaptic inputs in these interneurons. Nonetheless, it has been previously shown that TBS delivered in the O/A region reliably induces postsynaptic firing of $\mathrm{O} / \mathrm{A}$ interneurons in cell-attached recordings and results in a mGluR1a-mediated long-lasting potentiation of synaptically evoked firing of O/A cells (Croce et al., 2010). The present findings thus indicate that mGluR1a Hebbian LTP of feedback excitatory inputs to SOM-INs translates into a durable increase in their output firing, which made it a key component in the regulation of the input-output function in SOM-INs.

\section{Metaplasticity in the CA1 hippocampal network}

Understanding the specific contributions of the various GABAergic interneuron subtypes in the control of information flow within the cortico-hippocampal network is an important question. SOM-INs constitute a group of interneurons sharing the property to inhibit pyramidal cell and interneuron dendrites conferring them a crucial role in regulating the gain of pyramidal neuron input-output transformations (Pouille and Scanziani, 2004). Experiments using pharmacogenetic and optogenetic approaches have demonstrated that a specific silencing of hippocampal CA1 SOM-INs increases pyramidal cells firing rates and burst spiking during SC stimulation in vitro (Lovett-Barron et al., 2012; but see Wilson et al., 2012 for an opposite role in the visual cortex) and during spatial mapping in vivo (Royer et al., 2012).

However, SOM-INs are a nonhomogeneous population. For example, in hippocampal CA1, OLM cells densely synapse within the SLM to inhibit the pyramidal cell distal 
dendritic tuft, at the level of their temporo-ammonic inputs from the entorhinal cortex, whereas bistratified cells inhibit more proximal pyramidal cell dendrites in the stratum radiatum where they receive their inputs from SC (for review, see Klausberger, 2009; Müller and Remy, 2014). It has been shown that OLM neurons, themselves being less homogeneous than initially thought (Chittajallu et al., 2013), restrict voltage signals by providing a direct inhibition to the pyramidal cell dendritic tuft in response to temporo-ammonic stimulation, preventing their propagation along proximal dendrites (Leão et al., 2012). In addition, specific optogenetic stimulation of OLM cells increase SC-evoked excitatory synaptic responses and LTP by disinhibiting these synapses in pyramidal cells (Leão et al., 2012). Indeed, OLM cells also inhibit several classes of interneuron (Katona et al., 1999; Elfant et al., 2008; for review, see Chamberland and Topolnik, 2012), including SC-associated interneurons at the border of the stratum radiatum and the SLM, and to a lesser extent, bistratified cells (Leão et al., 2012), that are both coaligned with SC inputs. The present results reveal a form of metaplasticity in which mGluR1a LTP occurring at excitatory synapses onto SOM-INs specifically increases LTP magnitude at SC-PC synapses. This suggests that mGluR1a-mediated LTP induction in SOM-INs provide a disinhibition of SC-PC synapses, likely via the inhibition of interneurons in the stratum radiatum, and support an interneuron input-specific control of pyramidal cell integrative function. In our field potential recording experiments, TBS in oriens may have induced NMDARmediated LTP at synapses onto PV-INs (Le Roux et al., 2013). However, because selective optogenetic inactivation of SOM-INs during TBS or antagonism of mGluR1a receptors prevented the metaplasticity of LTP in the SC pathway, our results suggest that non-mGluR1amediated LTP at synapses onto PV-INs may not contribute to this metaplasticity.

Other forms of disinhibitory metaplasticity have been reported in CA1 PCs, but with a direct disinhibition of SC-pyramidal cells synapses through LTD of inhibitory synapses (I-LTD), i.e. plasticity of the output synapses of interneurons. They involve a specific contribution of cholecystokinin-expressing interneurons of the stratum radiatum in the dynamic segregation of SC and temporoammonic inputs (Basu et al., 2013), with a prominent role of group I mGluRs (Chevaleyre and Castillo, 2003, 2004; Basu et al., 2013; Xu et al., 2014), associated with the ability to support temporal associative memories (Xu et al., 2014). Taking into consideration that a learning episode increases intrinsic excitability in CA1 SOM-INs (McKay et al., 2013), this suggests that these interneurons may be endowed with multiple plasticity mechanisms to increase output function (input synapses, intrinsic excitability, and output synapses), probably acting in concerted fashion.

\section{Consequences for learning and memory}

A growing body of information is accumulating about the specific role of SOM-INs in cognitive abilities, mainly occurring via disinhibition mechanisms. In the anterior cingulate cortex, they participate in decision making (Kvitsiani et al., 2013) and they support and modulate sensory processing in different neocortical areas through a VIPSOM-IN-dependent disinhibition of principal cells (Lee et al., 2013; Pi et al., 2013; Zhang et al., 2014). They mediate precise visual processing by inhibiting PV-INs in the primary visual cortex (Cottam et al., 2013). They are inhibited by PV-INs to disinhibit PC dendrites in the basolateral amygdala during auditory-cued fear conditioning (Wolff et al., 2014); they mediate fear learning and produce fear expression through disinhibition mechanisms in the central amygdala (Li et al., 2013; Penzo et al., 2015). Within the hippocampus, CA1 OLM and bistratified cells rhythmically modulate pyramidal neurons activity in vivo (Klausberger et al., 2003, 2004; Katona et al., 2014). During fear conditioning, SOM-INs from the CA1 area, in particular the OLM cells, are believed to respond specifically to the unconditioned aversive stimulus, and by a direct inhibition, restrict the size of the coding pyramidal cell population (Lovett-Barron et al., 2014). Similarly, contextual fear conditioning increases the number of mossy fibers synaptic contacts onto interneurons in CA3, restricting the size of the coding pyramidal population and promoting memory precision (Ruediger et al., 2011). In the present study, we show that LTP occurring at excitatory synapses onto SOM-INs increases the magnitude of subsequent LTP at SC-PC synapses. This suggests that a disinhibition might occur in a subpopulation of principal neurons displaying an increased LTP (see above in Discussion). However, it does not exclude that repetitive pyramidal firing could also durably increase feedback and lateral direct inhibition to a different subpopulation of pyramidal neurons (Dupret et al., 2013).

Finally, a late form of LTP, induced by mGluR1a activation, dependent on transcription and translation via the mTORC1 pathway and lasting at least $24 \mathrm{~h}$, has recently been shown in CA1 O/A INs (Ran et al., 2009, 2012), suggesting that a persistent form of LTP may play a crucial role in the long-lasting metaplastic regulation of CA1 network activity during hippocampus-dependent learning and memory.

\section{References}

Basu J, Srinivas KV, Cheung SK, Taniguchi H, Huang ZJ, Siegelbaum SA (2013) A cortico-hippocampal learning rule shapes inhibitory microcircuit activity to enhance hippocampal information flow. Neuron 79:1208-1221. CrossRef Medline

Baude A, Nusser Z, Roberts JD, Mulvihill E, Mcllhinney RA, Somogyi $P$ (1993) The metabotropic glutamate receptor (mGluR1 alpha) is concentrated at perisynaptic membrane of neuronal subpopulations as detected by immunogold reaction. Neuron 11:771-787. Medline

Blasco-lbáñez JM, Freund TF (1995) Synaptic input of horizontal interneurons in stratum oriens of the hippocampal CA1 subfield: structural basis of feed-back activation. Eur J Neurosci 7:21702180. Medline

Chamberland S, Topolnik L (2012) Inhibitory control of hippocampal inhibitory neurons. Front Neurosci 6:165. CrossRef Medline

Chevaleyre V, Castillo PE (2003) Heterosynaptic LTD of hippocampal GABAergic synapses: a novel role of endocannabinoids in regulating excitability. Neuron 38:461-472. Medline 
Chevaleyre V, Castillo PE (2004) Endocannabinoid-mediated metaplasticity in the hippocampus. Neuron 43:871-881. CrossRef Medline

Chittajallu R, Craig MT, McFarland A, Yuan X, Gerfen S, Tricoire L, Erkkila B, Barron SC, Lopez CM, Liang BJ, Jeffries BW, Pelkey KA, McBain CJ (2013) Dual origins of functionally distinct O-LM interneurons revealed by differential $5-\mathrm{HT}(3 \mathrm{~A}) \mathrm{R}$ expression. Nat Neurosci 16:1598-1607. CrossRef Medline

Cottam JC, Smith SL, Häusser M (2013) Target-specific effects of somatostatin-expressing interneurons on neocortical visual processing. J Neurosci 33:19567-19578. CrossRef Medline

Croce A, Pelletier JG, Tartas M, Lacaille JC (2010) Afferent-specific properties of interneuron synapses underlie selective long-term regulation of feedback inhibitory circuits in CA1 hippocampus. $J$ Physiol 588:2091-2107. CrossRef Medline

Dupret D, O'Neill J, Csicsvari J (2013) Dynamic reconfiguration of hippocampal interneuron circuits during spatial learning. Neuron 78:166-180. CrossRef Medline

Elfant D, Pál BZ, Emptage N, Capogna M (2008) Specific inhibitory synapses shift the balance from feedforward to feedback inhibition of hippocampal CA1 pyramidal cells. Eur J Neurosci 27:104-113. CrossRef Medline

Freund TF, Buzsáki G (1996) Interneurons of the hippocampus. Hippocampus 6:347-470. CrossRef Medline

Hainmuller T, Krieglstein K, Kulik A, Bartos M (2014) Joint CP-AMPA and group I mGlu receptor activation is required for synaptic plasticity in dentate gyrus fast-spiking interneurons. Proc Nat Acad Sci U S A 111:13211-13216. CrossRef

Hosp JA, Strüber M, Yanagawa Y, Obata K, Vida I, Jonas P, Bartos M (2014) Morpho-physiological criteria divide dentate gyrus interneurons into classes. Hippocampus 24:189-203. CrossRef Medline

Ishizuka N, Weber J, Amaral DG (1990) Organization of intrahippocampal projections originating from CA3 pyramidal cells in the rat. J Comp Neurol 295:580-623. CrossRef Medline

Kandel ER, Dudai Y, Mayford MR (2014) The molecular and systems biology of memory. Cell 157:163-186. CrossRef Medline

Katona I, Acsády L, Freund TF (1999) Postsynaptic targets of somatostatin-immunoreactive interneurons in the rat hippocampus. Neuroscience 88:37-55. Medline

Katona L, Lapray D, Viney TJ, Oulhaj A, Borhegyi Z, Micklem BR, Klausberger T, Somogyi P (2014) Sleep and movement differentiates actions of two types of somatostatin-expressing GABAergic interneuron in rat hippocampus. Neuron 82:872-886. CrossRef Medline

Kepecs A, Fishell G (2014) Interneuron cell types are fit to function. Nature 505:318-326. CrossRef Medline

Klausberger T (2009) GABAergic interneurons targeting dendrites of pyramidal cells in the CA1 area of the hippocampus. Eur $\mathrm{J}$ Neurosci 30:947-957. CrossRef Medline

Klausberger T, Somogyi P (2008) Neuronal diversity and temporal dynamics: the unity of hippocampal circuit operations. Science 321:53-57. CrossRef Medline

Klausberger T, Márton LF, Baude A, Roberts JD, Magill PJ, Somogyi $P$ (2004) Spike timing of dendrite-targeting bistratified cells during hippocampal network oscillations in vivo. Nat Neurosci 7:41-47. CrossRef Medline

Klausberger T, Magill PJ, Márton LF, Roberts JD, Cobden PM, Buzsáki G, Somogyi P (2003) Brain-state- and cell-type-specific firing of hippocampal interneurons in vivo. Nature 421:844-848. CrossRef Medline

Kullmann DM, Moreau AW, Bakiri Y, Nicholson E (2012) Plasticity of inhibition. Neuron 75:951-962. CrossRef Medline

Kvitsiani D, Ranade S, Hangya B, Taniguchi H, Huang JZ, Kepecs A (2013) Distinct behavioural and network correlates of two interneuron types in prefrontal cortex. Nature 498:363-366. CrossRef Medline

Lamsa K, Heeroma JH, Kullmann DM (2005) Hebbian LTP in feedforward inhibitory interneurons and the temporal fidelity of input discrimination. Nat Neurosci 8:916-924. CrossRef Medline
Lamsa KP, Heeroma JH, Somogyi P, Rusakov DA, Kullmann DM (2007) Anti-Hebbian long-term potentiation in the hippocampal feedback inhibitory circuit. Science 315:1262-1266. CrossRef Medline

Lapointe V, Morin F, Ratte S, Croce A, Conquet F, Lacaille JC (2004) Synapse-specific mGluR1-dependent long-term potentiation in interneurones regulates mouse hippocampal inhibition. J Physiol 555:125-135. CrossRef Medline[Mismatch]

Le Duigou C, Kullmann DM (2011) Group I mGluR agonist-evoked long-term potentiation in hippocampal oriens interneurons. J Neurosci 31:5777-5781. CrossRef Medline

Le Roux N, Cabezas C, Böhm UL, Poncer JC (2013) Input-specific learning rules at excitatory synapses onto hippocampal parvalbumin-expressing interneurons. J Physiol 591:1809-1822. CrossRef Medline

Leão RN, Mikulovic S, Leão KE, Munguba $H$, Gezelius $H$, Enjin $A$, Patra K, Eriksson A, Loew LM, Tort AB, Kullander K (2012) OLM interneurons differentially modulate $\mathrm{CA} 3$ and entorhinal inputs to hippocampal CA1 neurons. Nat Neurosci 15:1524-1530. CrossRef Medline

Lee S, Kruglikov I, Huang ZJ, Fishell G, Rudy B (2013) A disinhibitory circuit mediates motor integration in the somatosensory cortex. Nat Neurosci 16:1662-1670. CrossRef Medline

Li H, Penzo MA, Taniguchi H, Kopec CD, Huang ZJ, Li B (2013) Experience-dependent modification of a central amygdala fear circuit. Nat Neurosci 16:332-339. CrossRef Medline

Lovett-Barron M, Turi GF, Kaifosh P, Lee PH, Bolze F, Sun XH, Nicoud JF, Zemelman BV, Sternson SM, Losonczy A (2012) Regulation of neuronal input transformations by tunable dendritic inhibition. Nat Neurosci 15:423-430. CrossRef Medline

Lovett-Barron M, Kaifosh P, Kheirbek MA, Danielson N, Zaremba JD, Reardon TR, Turi GF, Hen R, Zemelman BV, Losonczy A (2014) Dendritic inhibition in the hippocampus supports fear learning. Science 343:857-863. CrossRef Medline

Lynch G, Kramar EA, Gall CM (2014) Protein synthesis and consolidation of memory-related synaptic changes. Brain Res. Advance online publication. CrossRef Medline

Mann EO, Paulsen O (2007) Role of GABAergic inhibition in hippocampal network oscillations. Trends Neurosci 30:343-349. CrossRef Medline

McKay BM, Oh MM, Disterhoft JF (2013) Learning increases intrinsic excitability of hippocampal interneurons. J Neurosci 33:54995506. CrossRef Medline

Müller C, Remy S (2014) Dendritic inhibition mediated by O-LM and bistratified interneurons in the hippocampus. Front Synaptic Neurosci 6:23. CrossRef Medline

Nissen W, Szabo A, Somogyi J, Somogyi P, Lamsa KP (2010) Cell type-specific long-term plasticity at glutamatergic synapses onto hippocampal interneurons expressing either parvalbumin or CB1 cannabinoid receptor. J Neurosci 30:1337-1347. CrossRef

Oren I, Nissen W, Kullmann DM, Somogyi P, Lamsa KP (2009) Role of ionotropic glutamate receptors in long-term potentiation in rat hippocampal CA1 oriens-lacunosum moleculare interneurons. $J$ Neurosci 29:939-950. CrossRef Medline

Ouardouz M, Lacaille JC (1995) Mechanisms of selective long-term potentiation of excitatory synapses in stratum oriens/alveus interneurons of rat hippocampal slices. J Neurophysiol 73:810-819. Medline

Pelletier JG, Lacaille JC (2008) Long-term synaptic plasticity in hippocampal feedback inhibitory networks. Prog Brain Res 169:241250. CrossRef Medline

Penzo MA, Robert V, Tucciarone J, De Bundel D, Wang M, Van Aelst L, Darvas M, Parada LF, Palmiter RD, He M, Huang ZJ, Li B (2015) The paraventricular thalamus controls a central amygdala fear circuit. Nature 519:455-459.

Perez Y, Morin F, Lacaille JC (2001) A hebbian form of long-term potentiation dependent on mGluR1a in hippocampal inhibitory interneurons. Proc Nat Acad Sci U S A 98:9401-9406. CrossRef Medline 
Pi HJ, Hangya B, Kvitsiani D, Sanders JI, Huang ZJ, Kepecs A (2013) Cortical interneurons that specialize in disinhibitory control. Nature 503:521-524. CrossRef Medline

Pouille F, Scanziani M (2004) Routing of spike series by dynamic circuits in the hippocampus. Nature 429:717-723. CrossRef Medline

Ran I, Laplante I, Lacaille JC (2012) CREB-dependent transcriptional control and quantal changes in persistent long-term potentiation in hippocampal interneurons. J Neurosci 32:6335-6350. CrossRef Medline

Ran I, Laplante I, Bourgeois C, Pépin J, Lacaille P, Costa-Mattioli M, Pelletier J, Sonenberg N, Lacaille JC (2009) Persistent transcription- and translation-dependent long-term potentiation induced by mGluR1 in hippocampal interneurons. J Neurosci 29: 5605-5615. CrossRef Medline

Royer S, Zemelman BV, Losonczy A, Kim J, Chance F, Magee JC, Buzsáki G (2012) Control of timing, rate and bursts of hippocampal place cells by dendritic and somatic inhibition. Nat Neurosci 15: 769-775. CrossRef Medline

Ruediger S, Vittori C, Bednarek E, Genoud C, Strata P, Sacchetti B, Caroni P (2011) Learning-related feedforward inhibitory connectivity growth required for memory precision. Nature 473:514-518. CrossRef Medline

Somogyi P, Klausberger T (2005) Defined types of cortical interneurone structure space and spike timing in the hippocampus. J Physiol 562:9-26. CrossRef Medline

Szabo A, Somogyi J, Cauli B, Lambolez B, Somogyi P, Lamsa KP (2012) Calcium-permeable AMPA receptors provide a common mechanism for LTP in glutamatergic synapses of distinct hippocampal interneuron types. J Neurosci 32:6511-6516. CrossRef

Taniguchi H, He M, Wu P, Kim S, Paik R, Sugino K, Kvitsiani D, Fu Y, Lu J, Lin Y, Miyoshi G, Shima Y, Fishell G, Nelson SB, Huang ZJ (2011) A resource of Cre driver lines for genetic targeting of GABAergic neurons in cerebral cortex. Neuron 71:995-1013. CrossRef Medline
Topolnik L (2012) Dendritic calcium mechanisms and long-term potentiation in cortical inhibitory interneurons. Eur J Neurosci 35: 496-506. CrossRef Medline

Topolnik L, Azzi M, Morin F, Kougioumoutzakis A, Lacaille JC (2006) mGluR1/5 subtype-specific calcium signalling and induction of long-term potentiation in rat hippocampal oriens/alveus interneurones. J Physiol 575:115-131. CrossRef Medline

Tricoire L, Pelkey KA, Erkkila BE, Jeffries BW, Yuan X, McBain CJ (2011) A blueprint for the spatiotemporal origins of mouse hippocampal interneuron diversity. J Neurosci 31:10948-10970. CrossRef Medline

van Hooft JA, Giuffrida R, Blatow M, Monyer H (2000) Differential expression of group I metabotropic glutamate receptors in functionally distinct hippocampal interneurons. J Neurosci 20:35443551. Medline

Wilson NR, Runyan CA, Wang FL, Sur M (2012) Division and subtraction by distinct cortical inhibitory networks in vivo. Nature 488:343-348. CrossRef Medline

Wittner L, Henze DA, Záborszky L, Buzsáki G (2007) Threedimensional reconstruction of the axon arbor of a CA3 pyramidal cell recorded and filled in vivo. Brain Struct Funct 212:75-83. CrossRef Medline

Wolff SB, Gründemann J, Tovote P, Krabbe S, Jacobson GA, Müller C, Herry C, Ehrlich I, Friedrich RW, Letzkus JJ, Lüthi A (2014) Amygdala interneuron subtypes control fear learning through disinhibition. Nature 509:453-458. CrossRef Medline

Xu J, Antion MD, Nomura T, Kraniotis S, Zhu Y, Contractor A (2014) Hippocampal metaplasticity is required for the formation of temporal associative memories. J Neurosci 34:16762-16773. CrossRef Medline

Zhang S, Xu M, Kamigaki T, Hoang Do JP, Chang WC, Jenvay S, Miyamichi K, Luo L, Dan Y (2014) Selective attention: long-range and local circuits for top-down modulation of visual cortex processing. Science 345:660-665. CrossRef Medline 